\title{
Assessment of Conditional Symmetric Instability from Global Reanalysis Data
}

\author{
Ting-Chen Chen, M. K. YAU, AND DANIEl J. KIRSHBAum \\ Department of Atmospheric and Oceanic Sciences, McGill University, Montreal, Quebec, Canada
}

(Manuscript received 31 July 2017, in final form 6 April 2018)

\begin{abstract}
Slantwise convection, the process by which moist symmetric instability is released, has often been linked to banded clouds and precipitation, especially in frontal zones within extratropical cyclones. Studies also suggest that the latent heat release associated with slantwise convection can lead to a spinup of surface frontogenesis, which can enhance the rapid intensification of extratropical cyclones. However, most of these studies considered only local areas or short time durations. In this study, we provide a novel statistical investigation of the global climatology of the potential occurrence of slantwise convection, in terms of conditional symmetric instability, and its relationship with precipitating systems. Using the 6-hourly ERA-Interim, two different indices are calculated, namely, slantwise convective available potential energy (SCAPE) and vertically integrated extent of realizable symmetric instability (VRS), to assess the likelihood of occurrence of slantwise convection around the globe. The degree of association is quantified between these indices and the observed surface precipitation as well as the cyclone activity. The susceptibility of midlatitude cyclones to slantwise convection at different stages of their life cycle is also investigated. As compared to the nonexplosive cyclone cases, the time evolution of SCAPE and VRS within rapidly deepening cyclones exhibit higher values before, and a more significant drop after, the onset of rapid intensification, supporting the idea that the release of symmetric instability might contribute to the intensification of storms.
\end{abstract}

\section{Introduction}

Moist symmetric instability (SI) is an important mesoscale process in the atmosphere (Bennetts and Hoskins 1979; Emanuel 1983a). Slantwise convection, the process by which moist SI is released, has been associated with banded clouds and precipitation, especially in frontal zones within extratropical cyclones (e.g., Emanuel 1983b; Reuter and Yau 1993; Balasubramanian and Yau 1994; Thorpe and Emanuel 1985; Glinton et al. 2017, hereafter G17). This quasi-two-dimensional circulation is found mostly in regions with strong baroclinicity and vertical wind shear, oriented along an axis roughly parallel to the direction of the thermal wind (e.g., Seltzer et al. 1985). The width of the bands ranges from 50 to $500 \mathrm{~km}$ and the length varies considerably with cases, but with a general order of several hundred kilometers (e.g., Emanuel 1983a; Huang 1991).

The concept of symmetric instability represents an extension of static/gravitational instability and inertial instability, with the former related to the buoyancy force

\footnotetext{
Corresponding author: Ting-Chen Chen, ting-chen.chen@mail. mcgill.ca
}

and the latter arising from the imbalance of the pressure gradient and inertial (e.g., centrifugal or Coriolis) forces. The term "symmetric" refers to the two-dimensional nature (with no variation in the direction of the thermal wind vector, here taken as the $x$ direction) of the hypothetical system used to derive the instability condition. In a statically and inertially stable environment, the slantwise displacement of an air tube aligned with the $x$ axis may become unstable if the potential temperature surfaces are sloped more steeply than the geostrophic absolute momentum surfaces in the $y-z$ plane [see Markowski and Richardson (2010, chapter 3.4) for a schematic illustration]. In that event, an air tube displaced along the latter surfaces would accelerate away from its original position under the power of the buoyancy force. For a moist atmosphere, a similar condition for potential symmetric instability applies when the potential temperature is replaced by the equivalent potential temperature, and conditional symmetric instability (CSI) results when the potential temperature is replaced by the saturation equivalent potential temperature (Schultz and Schumacher 1999).

Moreover, analogous to how convective available potential energy (CAPE) can be used to estimate the 
strength of upright convection, slantwise CAPE (SCAPE), defined as the maximum kinetic energy that can be released by a lifted air tube (instead of an air "parcel" for CAPE) along a slanted trajectory, can be used to estimate the maximum strength of slantwise convection. Through the release of CSI, an adjustment takes place that eliminates the environmental SCAPE. A slantwise conditionally neutral state then results with the saturated equivalent potential temperature surfaces parallel to the absolute momentum surfaces. This slantwise neutral state is often observed in mature convective systems in baroclinic environments (e.g., Emanuel 1983b; Kuo et al. 1991; Reuter and Yau 1990, 1993).

In addition to its association with precipitation bands, CSI has also been linked to the explosive development of extratropical cyclones. From the analysis of sounding observations, Reuter and Yau (1993) found that, $12 \mathrm{~h}$ before the rapid intensification of a cyclone, the boundary layer ahead of the cyclone track was neutral or slightly stable for upright convection but unstable for slantwise convection. Sometime later, deep convective plumes were observed near the surface low center at the stage of explosive cyclogenesis. Numerical modeling studies have shown that the release of latent heat in slantwise convection may increase the rate of surface frontogenesis (e.g., Thorpe and Emanuel 1985). By conducting numerical experiments with and without a parameterization for slantwise convection, Balasubramanian and Yau (1994) found that simulated midlatitude cyclogenesis is sharper with the inclusion of slantwise convection, and that the onset of the rapid spinup coincides with the formation of a bent-back warm front, which is spatially overlapped with the maximum geostrophic vorticity.

Consistent results were obtained by Kuo et al. (1991) in a numerical simulation of a rapidly intensifying extratropical marine cyclone. They found that the heaviest simulated precipitation takes place over the warmfrontal region where the pressure rapidly drops and the maximum latent heating is observed. The conjunction of diabatic process and the frontal upglide motion creates a positive feedback loop, reinforcing the lowlevel frontogenesis. However, the association between slantwise convection potential and explosive cyclogenesis is not always obvious. Shutts (1990a,b) examined the prestorm condition for eight cyclones simulated by the Met Office's fine-mesh model, finding that large SCAPE (over $1000 \mathrm{~J} \mathrm{~kg}^{-1}$ ) appears in two out of five explosive cyclogeneses and one out of three nonexplosive cases. Some uncertainty in the relationship between slantwise convection and midlatitude cyclogenesis may relate to the inability of numerical models to explicitly describe this convection with limited grid resolution (Shutts 1990a,b). Also, the SCAPE diagnoses in Shutts (1990a,b) were only shown at a specific analysis time for each case, so it is unclear how SCAPE evolves over the life cycle of the developing cyclones.

Whereas previous work on CSI and banded precipitation were mostly case studies, G17 examined the climatologies of SCAPE and a metric called vertically integrated extent of realizable symmetric instability (VRS); a measure to quantify the "releasable" CSI [see more in section 2a(2)] over the North Atlantic and European region using the ERA-Interim data. They found that, at any given time in winter, there is an approximately $20 \%$ chance that slantwise convection is occurring somewhere over the western North Atlantic Gulf Stream region. When slantwise convection occurs, the maximum vertical extent in each air column over which the CSI is likely to be released has an averaged cumulative depth of $1 \mathrm{~km}$ and above. To quantify the contribution of CSI to the climatological precipitation, they first calculated the Pearson correlation coefficient between the daily averaged CAPE or SCAPE and the corresponding 24-h accumulated precipitation from the Hadley Centre U.K. precipitation (HadUKP) dataset, both of which were first averaged over the United Kingdom, and obtained a climatological (January 1979December 2010) value of 0.21 and 0.43 , respectively. This result indicates that the contribution of slantwise convection to the precipitation in the United Kingdom may be significant. For the larger North Atlantic and European region, the ERA-Interim precipitation data were used. They found that the correlation between precipitation and SCAPE is around $0.05-0.1$ higher than between precipitation and CAPE across most of the North Atlantic Gulf Stream region and the central North Atlantic, with a peak difference of up to 0.15 near the eastern U.S. coastline in winter, autumn, and spring.

Whereas ample evidence exists that CSI is an important mechanism for the formation or enhancement of some banded convective systems, most of the literature has focused on limited geographic extent at synoptic time scales. A global analysis of thermal stratification by Korty and Schneider (2007) found that the frequency of convectively (upright and/or slantwise) neutral air masses is common not only in the tropics but also in oceanic regions around the midlatitude storm tracks, and Zamora et al. (2016) showed similar patterns in global climate models. To our knowledge, Ma (2000) was the first to produce a global climatology of SCAPE, using the ERA-15 data for 1979-1993. While he suggested that moderate SCAPE may strongly influence precipitation in midlatitude oceans in the winter hemisphere, the links between the two were not quantified. The aim of this study is twofold. The first goal is to investigate the susceptibility of the atmosphere to CSI 
around the globe using a more recent, updated reanalysis dataset that covers a longer time span than that considered by Ma (2000). Second, we statistically quantify the association between slantwise convection potential and the related observed weather phenomena, such as precipitation and cyclone frequency as well as intensification rate. Some of the analysis is similar to G17 but extended to the global domain.

The organization of the paper is as follows. In section 2 , the global reanalysis dataset used in this study, the indices for the assessment of CSI, and the reanalysisbased precipitation and cyclone data for the comparison are introduced. Results are shown in section 3, connecting the climatology of slantwise convection potential with its correlation to the precipitation and cyclone activity. Finally, section 4 presents the summary.

\section{Data and methods}

The assessment of CSI over the globe is conducted using the global reanalysis dataset ERA-Interim, from the European Centre for Medium-Range Weather Forecasts (ECMWF). The spatial resolution is $0.75^{\circ} \times$ $0.75^{\circ}$ on 37 vertical levels from 1000 up to $1 \mathrm{hPa}$, and the temporal resolution is every $6 \mathrm{~h}$ over the period January 1979-December 2015. Caveats on the usage of reanalysis data include the inadequacy of its resolution in resolving CSI and the lack of a slantwise convective parameterization in the production of such products. Nevertheless, G17 mentioned that CSI can still be ultimately released via the convection scheme if CSI is converted to conditional instability, a process suggested by a few studies (e.g., Xu 1986; Gray et al. 2011). Glinton (2013) compared the VRS climatology between ERA-Interim and the CSI-release-permitting Met Office Unified Model (MetUM), version 7.3, run over the North Atlantic and European region (NAE) (with approximately 12-km horizontal grid spacing) and concluded that CSI release can still be quantified to some extent using ERA-Interim. Furthermore, there is evidence to suggest that, despite the coarse resolution, patterns of saturation potential vorticity consistent with slantwise convective adjustment are present in global models (Zamora et al. 2016).

\section{a. Assessment of symmetric instability}

There are several measures to assess different types of symmetric instability (Schultz and Schumacher 1999). Here, we utilize two different indices, mainly related to CSI, to identify the potential occurrence of slantwise convection. These indices are calculated every $6 \mathrm{~h}$ and their long-term averages are presented. The surface pressure field is used to exclude the data below Earth's surface (e.g., over high terrain).

\section{1) SCAPE}

SCAPE represents the maximum potential energy that can be released during the lifting of a hypothetical air tube along a sloping trajectory. Along with SCAPE, CAPE is also calculated to gain insight into the relative occurrence of upright convection and slantwise convection all over the globe. Note that the calculations of CAPE and SCAPE can be sensitive to different assumptions. Here, the pseudoadiabatic ascent of a parcel from the lowest 50 -hPa mixed layer above the surface is assumed, and ice-phase transitions are not considered. CAPE, the vertically integrated positive buoyancy of the parcel, is defined as the vertical integral of positive temperature difference between the parcel and its surrounding environment:

$$
\mathrm{CAPE}=\int_{\mathrm{LFC}}^{\mathrm{LNB}}\left[R_{d}\left(T_{v t}-T_{v e}\right)\right] d(-\ln p),
$$

where $T_{v t}$ and $T_{v e}$ are the virtual temperature of the lifted air and of the environment, respectively, and $R_{d}$ is the gas constant for dry air. The above integral yields positive values between the level of free convection (LFC) and the level of neutral buoyancy (LNB) of the lifted parcel.

The theoretical maximum available potential energy for slantwise convection, SCAPE, is diagnosed by evaluating the integrand in Eq. (1) on a geostrophic absolute momentum surface, $M=u_{g}-f y$, where $f$ is the Coriolis parameter, $u_{g}$ is the geostrophic flow, and $y$ is defined as $90^{\circ}$ counterclockwise of the thermal wind. This integral is confined to the layer over which the temperature difference between the mixed-layer air tube and the surrounding environment, during the lifting along the $M$ surface, is positive. The lower and upper limits are defined as the level of free slantwise convection (LFSC) and the level of slantwise neutral buoyancy (LSNB), respectively:

$$
\text { SCAPE }=\int_{M}^{\mathrm{LSNB}}\left[R_{d}\left(T_{v t}-T_{v e}\right)_{M}\right] d(-\ln p) .
$$

Note that the environmental temperature in the above formula is measured along the $M$ surface on which the air tube is lifted. In a shallow barotropic atmosphere, $M$ surfaces are oriented vertically and thus the above formula for SCAPE becomes identical to the one for CAPE. Hence, the difference between SCAPE and CAPE can be regarded as the contribution from baroclinicity.

For computational efficiency, we adopt an estimated formula for SCAPE that can be obtained in each vertical column (Emanuel 1983b): 


$$
\begin{aligned}
\mathrm{SCAPE}= & \int_{\mathrm{LFSC}}^{\mathrm{LSNB}}\left[R_{d}\left(T_{v t}-T_{v e}\right)+\frac{1}{2} \frac{f}{\eta} \frac{d\left(u-u_{0}\right)^{2}}{d(-\ln p)}\right] \\
& \times d(-\ln p)
\end{aligned}
$$

where $u$ is the horizontal wind component in the direction of the thermal wind and is assumed to be close to geostrophic, $u_{0}$ is the initial $u$ of the lifted tube, and $\eta$ is the absolute geostrophic vorticity, here defined as $f-\partial u / \partial y$ on pressure levels. The first term shown in Eq. (3) represents the gravitational contribution to the potential energy, defined as the static term, while the second term indicates the contribution from the inertial force (i.e., the symmetric term). Note that there are several assumptions contained in Eq. (3). First, the vertical shear is assumed to be nearly unidirectional. Second, the component of the flow in the direction of the column-averaged shear at each level is assumed to be close to geostrophic. Last, at each level, the horizontal gradients of $M$ are assumed to be constant between the initial location of the lifted tube and the sloped $M$ surface along which the air tube is hypothetically lifted. The first assumption is approximately valid for two-dimensional systems, such as the frontal zones of extratropical cyclones. Previous work investigating the validity of two-dimensional theory for three-dimensional flows has indicated that a time-scale separation must be assumed between a relatively rapid time scale for ascent and a slower time scale for the evolution of the flow (e.g., Gray and Thorpe 2001). The second assumption is generally satisfied in baroclinic systems. The validity of the third assumption was discussed in Emanuel (1983b). He showed that this condition is frequently met for large-scale flows for which the Rossby number is small. Furthermore, a comparison between our calculated SCAPE using Eq. (3) and the results shown in G17, in which Eq. (2) is used, exhibits very similar SCAPE distribution within cyclones (not shown), suggesting that this simplification is likely to have little impact on our results.

While CAPE has been widely used in both research applications and operational centers to diagnose the potential occurrence of severe convective weather or precipitating events (e.g., Brooks et al. 2003; Marsh et al. 2007; Subrahmanyam et al. 2015), it is proposed in G17 that SCAPE can be a superior index for this purpose since it not only includes the available potential energy associated with moist static instability (CAPE) but also accounts for the presence of moist symmetric instability. Their analyses over the United Kingdom and North Atlantic support this notion. In the present study, comparison of the correlation coefficient between SCAPE and CAPE with precipitation analysis is extended to the entire globe.

\section{2) VRS}

While SCAPE provides a measure of the likelihood of moist convection (including both upright and slantwise) from the perspective of maximum available energy, such energy can only be released if a lifting mechanism exists to bring the air to its LFSC. Based on an ingredient-based methodology for forecasting deep, moist convection, three ingredients are required: instability, moisture, and lift (e.g., Schultz and Schumacher 1999). Following this idea, Dixon et al. (2002) developed the VRS diagnostic measure. Building on Dixon et al. (2002), Morcrette (2004), and G17, here we define VRS as the maximum continuous thickness in each air column where the following conditions are met simultaneously:

(i) Nearly saturated conditions. A moderate threshold of $\mathrm{RH}>90 \%$ is chosen in this study based on the systematic analysis of the impacts of relative humidity criteria on the VRS calculation in Glinton (2013).

(ii) Upward motion.

(iii) The presence of negative (positive) saturated geostrophic potential vorticity, MPV $V_{g}^{*}$, in the Northern (Southern) Hemisphere:

$f \mathrm{MPV}_{g}^{*}<0, \quad$ where $\mathrm{MPV}_{g}^{*}=\frac{1}{\rho}\left(\nabla \times \mathbf{V}_{g}+f \hat{z}\right) \cdot \nabla \theta_{e}^{*}$,

where $\rho$ is the air density, $\mathbf{V}_{g}$ is the geostrophic wind vector, $f$ is the Coriolis parameter, and $\theta_{e}^{*}$ is the saturation equivalent potential temperature. By defining the $y$ axis as $90^{\circ}$ counterclockwise of the column-averaged thermal winds, the geostrophic wind $u_{g}$ as the scalar component in the direction of the $x$ axis at each layer, and by expanding MPV $\mathrm{MP}_{g}^{*}$ in pressure coordinates together with invoking the hydrostatic approximation, we obtain

$$
\begin{aligned}
\mathrm{MPV}_{g}^{*} & =g\left[-\frac{\partial u_{g}}{\partial p} \frac{\partial \theta_{e}^{*}}{\partial y}-\left(f-\frac{\partial u_{g}}{\partial y}\right) \frac{\partial \theta_{e}^{*}}{\partial p}\right] \\
& =g\left[-\frac{\partial M}{\partial p} \frac{\partial \theta_{e}^{*}}{\partial y}-\left(-\frac{\partial M}{\partial y}\right) \frac{\partial \theta_{e}^{*}}{\partial p}\right] \\
& =-g\left(\nabla_{p} \theta_{e}^{*} \times \nabla_{p} M\right) \cdot \hat{x} .
\end{aligned}
$$

Note that Eq. (4) is equivalent to the aforementioned necessary condition of symmetric instability that the (saturated equivalent) potential temperature surfaces are sloped more steeply than the geostrophic absolute momentum surfaces in a vertical cross section normal to the thermal wind (see section 1).

(iv) The absence of both conditional (static/gravitational) instability and inertial instability, that is, $\partial \theta_{e}^{*} / \partial z>0$ and $f \eta_{g}>0$, where $\eta_{g}=f-\partial u_{g} / \partial y$, respectively. 
The fourth condition is added to exclude the contributions of inertial and static instability, and thus the combination of the third and fourth conditions defines the existence of pure CSI. The identification of SI based on geostrophic potential vorticity can be rewritten in terms of another frequently used measure, the Richardson number (Ri), defined as the ratio of the stratification to the vertical geostrophic wind shear (e.g., Stone 1966, 1967, 1971; Hoskins 1974; Seltzer et al. 1985; Reuter and Yau 1990; Dixon et al. 2002; O'Neill and Kaspi 2016). For the necessary condition of CSI, Eq. (4) is also equivalent to

$$
\frac{\eta}{f} \mathrm{Ri}_{m}<1
$$

where the moist Richardson number $\mathrm{Ri}_{m} \equiv N_{m}^{2} / V_{g z}^{2}=$ $\left[f(\delta z / \delta x)_{M_{g}}\right] /\left[\eta(\delta z / \delta x)_{\theta_{e}^{*}}\right], N_{m}$ is the saturated buoyancy frequency and $V_{g z}$ is the vertical geostrophic wind shear.

It can be deduced that large CSI requires a strong horizontal temperature gradient (and thus strong vertical wind shear outside the equatorial region) along with weak static and inertial stability (i.e., small Ri). Our calculation of VRS is based near the surface, or $1000 \mathrm{hPa}$, and extends up to $200 \mathrm{hPa}$, so it has an upper bound of $800 \mathrm{hPa}$ in depth. To compare with the climatology of cyclone tracks [see section $2 b(2)$ ], we only evaluate the VRS during the time period when both the ERA-Interim data and cyclone track data are available (January 1979-December 2008).

Note that there might be a degree of uncertainty in the geostrophic potential vorticity calculation near the equator since the geostrophic balance is not applicable there. Finally, we reiterate that the presence of SCAPE and/or VRS is a necessary but not sufficient condition for slantwise convection to be the locally dominant fluid-dynamical process.

\section{b. Reanalysis-based data}

To evaluate the relation between CSI and related weather phenomena, we utilize the reanalysis-based data as proxies of the real observations and compare their precipitation and cyclone activity analyses with the indices introduced above.

\section{1) Precipitation}

Given that upward motions cause condensation of water within clouds, vigorous moist convection with strong updrafts often gives rise to heavy precipitation. Because CAPE can be used to estimate the maximum upward motion that results from the buoyancy force (or the release of static instability), it is well correlated with the observed precipitation distribution in areas where deep convection dominates the precipitation climatology, especially when the analysis is conducted over a large spatial area and time period (e.g., Monkam 2002; Subrahmanyam et al. 2015).
Estimates of cumulative precipitation over a given time period vary with the forecast initialization time, and some studies have suggested that the cumulative precipitation forecast over $12-24 \mathrm{~h}$ (the start of the forecast is defined as $0 \mathrm{~h}$ ) is preferable to avoid model spinup over the first several hours of integration (e.g., Hawcroft et al. 2016). In contrast, some studies suggested that the 0-12-h forecast agrees best with other independent global precipitation estimates from the Global Precipitation Climatology Project (GPCP; Adler et al. 2003) and the Climate Prediction Center (CPC) Merged Analysis of Precipitation (CMAP; Xie and Arkin 1997; Kållberg 2011). Here, the 0-12-h forecast is chosen and the monthly average is computed. Studies have found that the ERA-Interim precipitation exhibits close agreement with these observational analyses on the monthly time scale (e.g., Simmons et al. 2010; Bromwich et al. 2011; Dee et al. 2011). However, biases and uncertainties also exist in the observational analyses, especially over the oceans, mountainous regions, and polar areas (e.g., Adler et al. 2003).

In contrast to the instantaneous correlations between CAPE/SCAPE and precipitation conducted by G17, we examine the correlations of monthly means. This approach, which was chosen for computational efficiency, is based on the assumption that temporal means of instantaneous correlations can be captured by correlations of monthly means. As will be seen, the similarities between our findings and those of G17 over their common region suggest that this assumption is reasonably valid.

\section{2) CyClones}

The cyclone data used in this study are obtained from Serreze (2009), which comprise a 50-yr record of cyclone statistics for the Northern Hemisphere from January 1958 to December 2008. In this dataset, cyclone locations are detected by applying the updated tracking algorithm of Serreze et al. (1997) to the sea level pressure fields from the NCEP-NCAR reanalysis at 6-h intervals. Cyclogenesis (cyclolysis) is identified at the time of the first (last) appearance of a closed 1-hPa isobar. To account for the latitudinal variation in geostrophic wind for a unit pressure gradient, sea level pressure values are adjusted by multiplying a latitude-dependent factor, $\sin \phi_{\text {ref }} / \sin \phi$, where $\phi_{\text {ref }}$ is a reference latitude of $60^{\circ} \mathrm{N}$ following Sanders and Gyakum (1980) and Serreze (1995) and $\phi$ is the latitude at each point (Serreze et al. 1997). While inconsistency might exist when applying different cyclone detection algorithms to different reanalysis data, here we neglect such potential impacts and target the most robust cyclone systems and discard some spurious ones associated with the reduction of surface pressure to sea level pressure over high topography. 
Therefore, cyclones that lasted for short durations $(<36 \mathrm{~h})$ and those remained nearly stationary (i.e., the cyclone center shifts less than $3^{\circ}$ among their first, midlifetime, and last observation) are eliminated in this study. We also identify cases with explosive cyclogenesis by examining whether they experienced a central surface pressure drop of more than $24 \mathrm{hPa}$ within $24 \mathrm{~h}$ at some point during their lifetime (Sanders and Gyakum 1980).

\section{Results}

\section{a. Global distribution of CAPE and SCAPE}

Before analyzing the climatological SCAPE, the seasonal distribution of 37-yr-averaged CAPE over the globe is first examined (Figs. 1a-d). The basic patterns are consistent with previous climatologies (e.g., Ma 2000; Riemann-Campe et al. 2009; G17), although uncertainty exists in peak values, especially over the terrain. The largest CAPE values lie between $30^{\circ} \mathrm{N}$ and $30^{\circ} \mathrm{S}$ focusing near the intertropical convergence zone (ITCZ) where warm and humid air prevails. Regional CAPE maxima are also observed over the Gulf of Mexico, the Amazon basin in South America, the southwestern North Pacific, the Bay of Bengal, and the Congo River basin in Africa, especially in June-August (JJA). The climatologically averaged CAPE ranges from 0 to $1800 \mathrm{~J} \mathrm{~kg}^{-1}$, and the interannual CAPE standard deviation has a general magnitude of $100-500 \mathrm{~J} \mathrm{~kg}^{-1}$. The standard deviation distribution is similar to the long-term-average CAPE distribution (not shown), indicating that areas with larger averaged CAPE also exhibit larger temporal variations. The seasonal variation of CAPE is more clearly illustrated in zonally averaged latitudinal profiles in Fig. 2a. As the maximum shifts to the Southern Hemisphere following the seasonal change from JJA to December-February (DJF), its value decreases as well, mainly because of the reduced land coverage in the Southern Hemisphere. The absolute maximum is located in the Northern Hemisphere rather than the Southern Hemisphere over all seasons except DJF.

The global distributions of the mean and standard deviation of SCAPE, as well as their zonally averaged profiles, are all similar to those of CAPE, except for slightly wider north-south extents. Figures $1 \mathrm{e}-\mathrm{h}$ display the global distribution of SCAPE minus CAPE $\gamma_{s}$. The spatial distribution of $\gamma_{s}$ is consistent with the results of Ma (2000). The values of $\gamma_{s}$ reach as high as $500 \mathrm{~J} \mathrm{~kg}^{-1}$, and large patches exceeding $100 \mathrm{~J} \mathrm{~kg}^{-1}$ are widespread over the oceans between $5^{\circ}$ and $40^{\circ} \mathrm{N}$ and between $5^{\circ}$ and $30^{\circ} \mathrm{S}$, where warm and humid air coincides with substantial vertical wind shear. Such subtropical patches of positive $\gamma_{s}$ are observable in all seasons and they extend farther northward in the North Atlantic and North Pacific Oceans in DJF when the strongest vertical wind shear is observed (e.g., Holton 2004, chapter 6.1). A local extremum in $\gamma_{s}$ is observed in the northern Indian Ocean in JJA, associated with the prevailing lowto midlevel monsoon that contributes greatly to the symmetric term of Eq. (3) over that area. Over the Antarctica region, small but negative $\gamma_{s}$ often arises from a negative symmetric term ( $M$ slightly decreases with height) in the low layers. The zonally averaged $\gamma_{s}$ displays a bimodal distribution (Fig. 2b), which largely does not shift in latitude with season but stays maximized in the subtropical and the lower midlatitude regions (Figs. 1e-h). The peak values of zonally averaged $\gamma_{s}$ are located near $14^{\circ} \mathrm{N}$ and $20^{\circ} \mathrm{S}$.

\section{b. Correlation of SCAPE and precipitation}

The large coincidence of precipitation and the CAPE distribution in tropical areas lends support to the predominant role of upright convection in the tropics (Figs. 1a-d). However, there is some precipitation (with an average of $>3 \mathrm{~mm} \mathrm{day}^{-1}$ ) in the midlatitude Pacific and Atlantic Oceans [extending poleward and eastward from $30^{\circ} \mathrm{N}\left(30^{\circ} \mathrm{S}\right)$ of the western part of the ocean to $60^{\circ} \mathrm{N}\left(60^{\circ} \mathrm{S}\right)$ ] coinciding with small or zero CAPE. Such inconsistency between CAPE and precipitation may be partially associated with the neglect of slantwise convection.

To quantify their associations, the correlation between the monthly averaged CAPE or SCAPE and the corresponding monthly precipitation during the period of January 1979-December 2015 at each grid point is calculated to obtain correlation maps for four different seasons. It should be borne in mind that neither CAPE nor SCAPE should be expected to correlate perfectly with precipitation, because these parameters neglect important effects such as water loading and entrainment processes, and because nonconvective processes (e.g., orographic lifting and symmetrically stable portions of baroclinic systems) also produce precipitation.

The correlation between CAPE and precipitation (Figs. 3a-d) is generally positive globally with local peak values of above 0.9 in subtropical areas in every season and in the Arctic area during winter. While the annual-mean CAPE is very small in the Arctic (Fig. 1), persistent negative anomalies of both CAPE and precipitation (relative to the annual mean) give rise to a large correlation over that time. Over the tropical and subtropical regions, this correlation generally exceeds 0.6 except over a nearly horizontal thin band along the equator, where the largest precipitation $\left(>8 \mathrm{~mm} \mathrm{day}^{-1}\right)$ is observed. This result is consistent with G17 in that, climatologically, CAPE has a stronger (weaker) association with precipitation in areas with light to moderate (heavy) precipitation. Specifically, while the infrequent instances of large CAPE in climatologically dry regions 


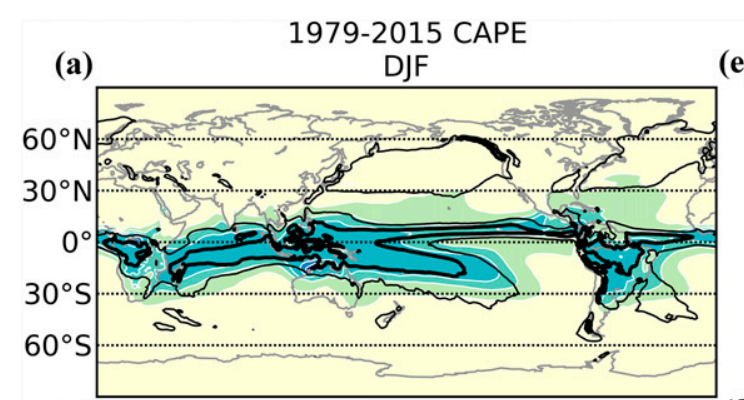

(e)

1979-2015 SCAPE-CAPE

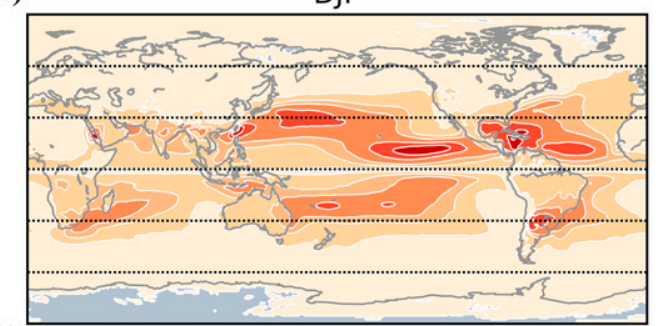

(b)

MAM

(f)
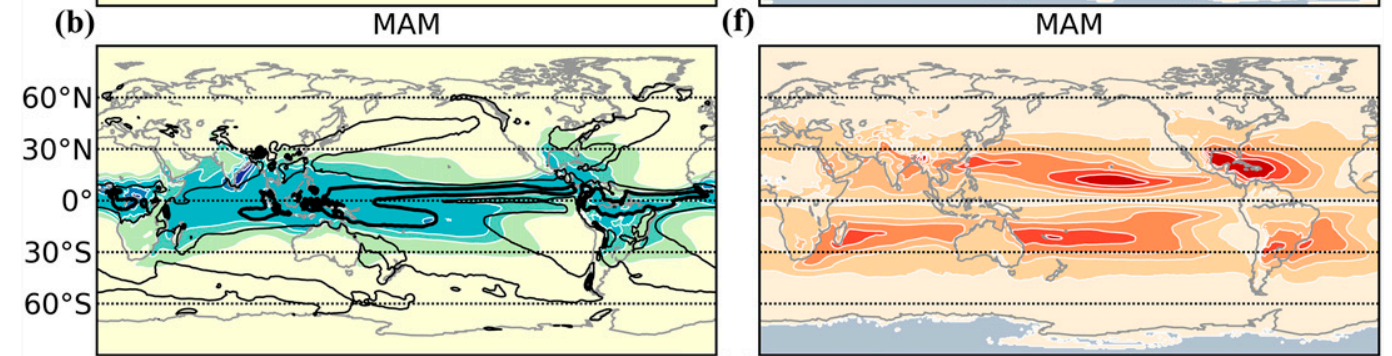

(c)

JJA

(g)

JJA
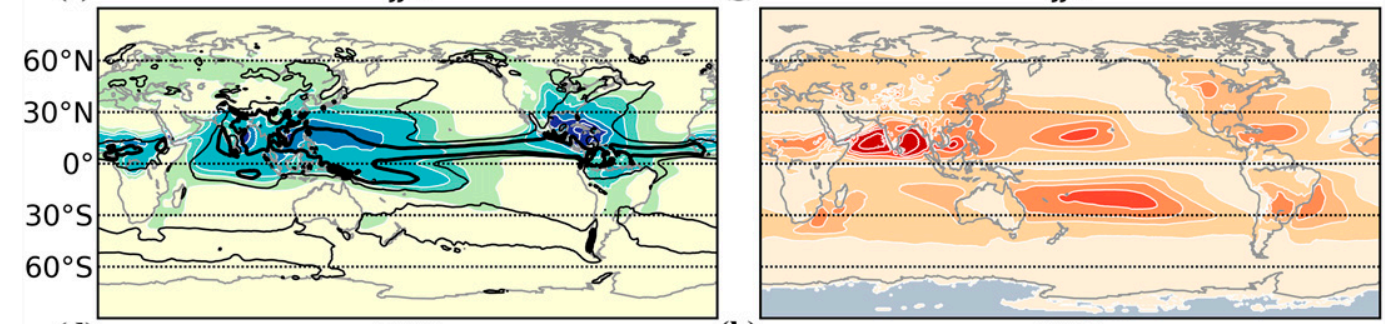

(d)

SON

(h)
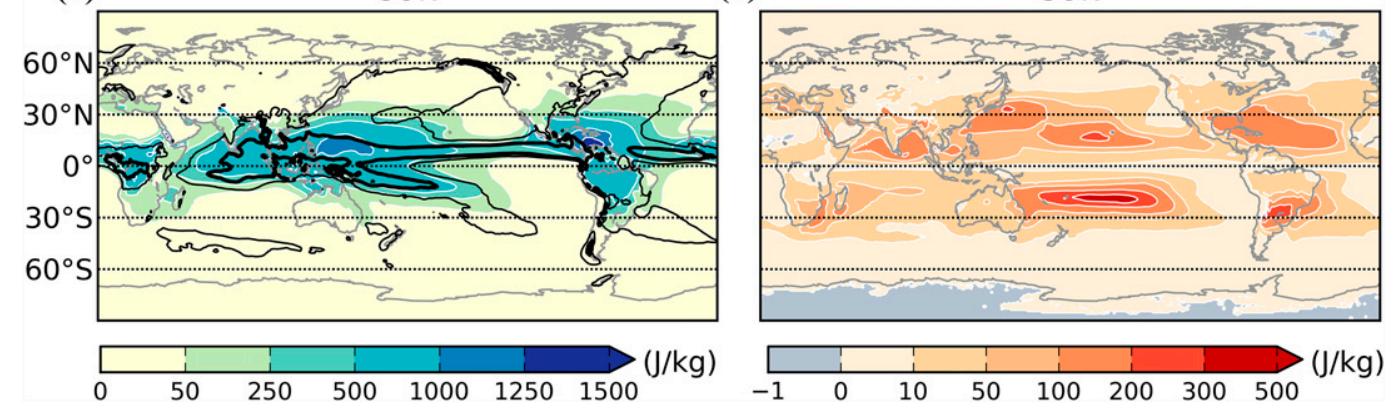

FIG. 1. The 37-yr-averaged global distribution of CAPE (shaded; $\mathrm{J} \mathrm{kg}^{-1}$ ) and precipitation [thin (thick) black contour indicates 3 (8) $\mathrm{mm} \mathrm{day}^{-1}$ ] for (a) DJF, (b) MAM, (c) JJA, and (d) SON during 1979-2015. (e)-(h) As in (a)-(d), respectively, but for the difference of SCAPE and CAPE $\gamma_{s}$ (shaded; $\mathrm{J} \mathrm{kg}^{-1}$ ).

tend to coincide with periods of heavier precipitation, the nearly continuous large CAPE in climatologically humid regions does not always coincide with precipitation. In the midlatitudes, negative correlations $(<-0.3)$ are frequently observed in the westernmost parts of North Atlantic and North Pacific, especially in DJF and JJA. Detailed analyses suggest that during DJF, moderate rainfall is still observed in these areas, but CAPE is generally smaller than its average value. The situation reverses in JJA when mostly positive CAPE fails to coincide with the occasional light rain (not shown).
Some such inconsistencies are ameliorated when SCAPE is used. Figures $3 \mathrm{e}-\mathrm{h}$ display the difference of precipitation correlation using SCAPE from the one using CAPE. Qualitatively consistent with the results shown in G17 for the North Atlantic and European region, SCAPE shows a higher correlation than CAPE with precipitation mainly in the midlatitudes. However, over the central to eastern tropical Pacific, SCAPE strongly exceeds CAPE yet the precipitation is only moderate (Fig. 1). A significantly higher $(>0.3)$ correlation difference is found mostly in midlatitude oceans around $30^{\circ}-40^{\circ} \mathrm{N}\left(30^{\circ}-40^{\circ} \mathrm{S}\right)$, particularly in DJF (JJA), suggesting that the precipitation 
(a) 1979-2015 Zonally-averaged SCAPE \& CAPE

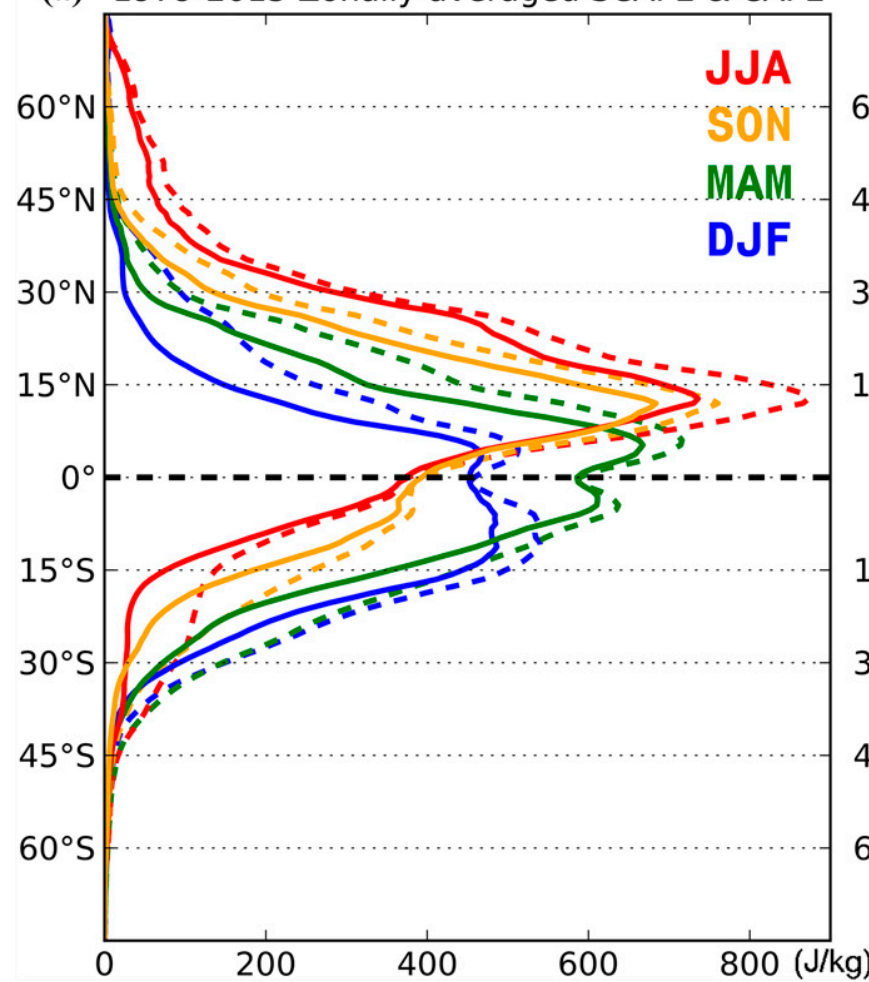

(b)

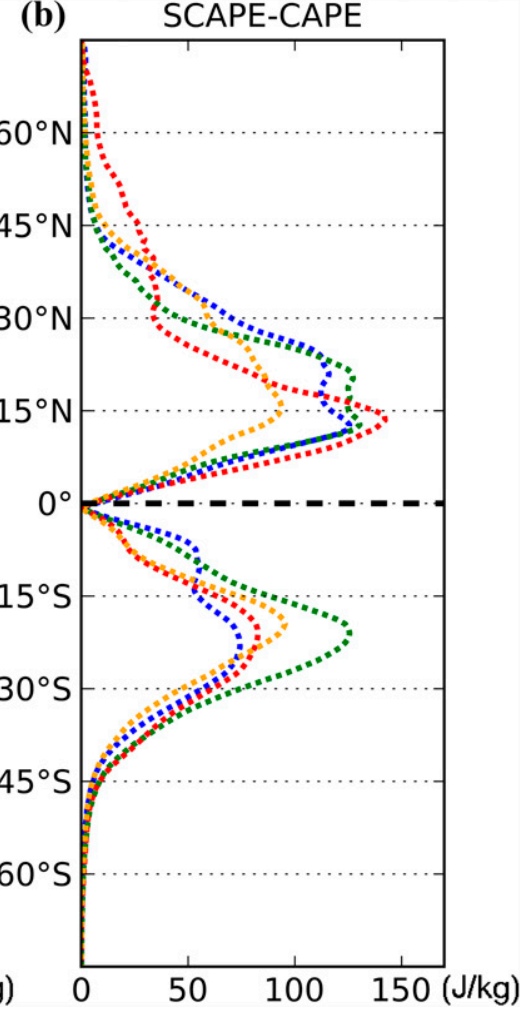

FIG. 2. (a) Zonal averages of CAPE (solid lines) and SCAPE (dashed lines) for JJA (red), SON (yellow), MAM (green), and DJF (blue) during 1979-2015. The calculation is made only when the value of CAPE (SCAPE) is greater than zero. (b) As in (a), but for the difference of SCAPE and CAPE. The calculation is made only when the difference is greater than zero.

contributed by slantwise convection is especially important over that area during the winter months. Note that these correlation coefficients are higher than those of G17, possibly because of our use of monthly means rather than 6-hourly diagnostics for correlation calculation. In terms of the domain average, both SCAPE and CAPE exhibit correlation coefficients on the order of $0.4-0.5$ and slightly smaller values of 0.3 over land (Table 1 ). By performing the Student's $t$ test, the correlation coefficients between CAPE (or SCAPE) and precipitation are generally found to be significantly different from zero at the $95 \%$ confidence level for a two-tailed test. In general, SCAPE provides the greatest improvement over CAPE in precipitation correlation in subtropical and midlatitude areas, with an annualaverage correlation coefficient difference of 0.06. Such enhancement is maximized in DJF and JJA, with correlation coefficient differences of 0.08 and 0.06 , respectively. Among all the ocean basins, the North Pacific and North Atlantic exhibit the highest domain-averaged correlation coefficients between SCAPE and precipitation, with annual values of 0.51 and 0.52 , respectively. The other domainaveraged correlation coefficients over different areas and during different seasons are summarized in Table 1.

\section{c. Global distribution of fractional SCAPE residual and VRS}

\section{1) FRACTIONAL SCAPE RESIDUAL}

The poorer correlation of SCAPE, relative to CAPE, with precipitation in the central to eastern Pacific (i.e., the large residual term $\gamma_{s}$ does not correspond to large precipitation there) suggests that upright convection may dominate in those areas despite the increased symmetric instability. This suggests a different way to gauge the relative importance of upright convection and slantwise convection. Thus, as an alternative to the absolute magnitude of the difference between SCAPE and CAPE, we define a fractional SCAPE residual as follows:

$$
f_{s}=\frac{\gamma_{s}}{\mathrm{SCAPE}}=\frac{\text { SCAPE }-\mathrm{CAPE}}{\mathrm{SCAPE}} .
$$

The value of $f_{s}$ ranges from 0 to 1 . When SCAPE $\approx$ CAPE (i.e., the atmosphere is close to barotropic or the vertical geostrophic wind shear is nearly 0 ), $f_{s} \approx 0$ and the area is favorable for upright convection. On the 

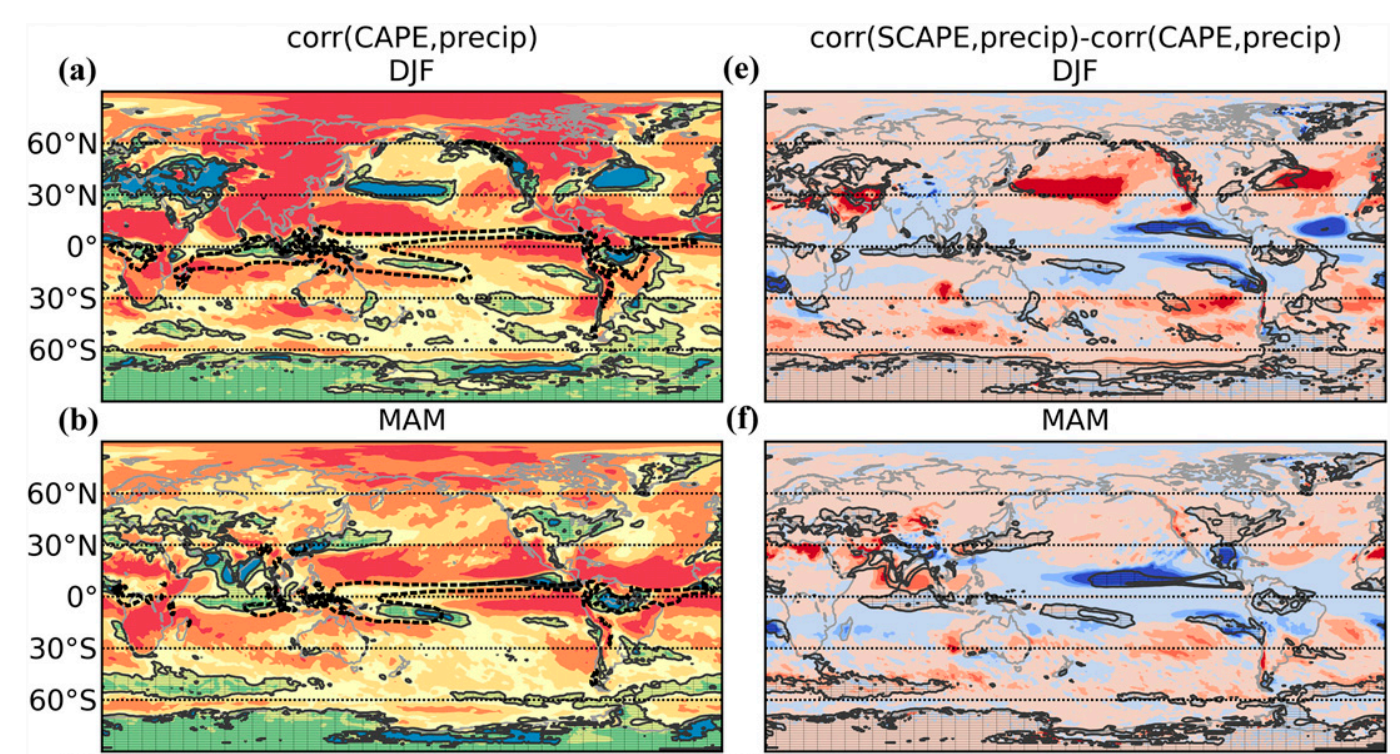

(f)
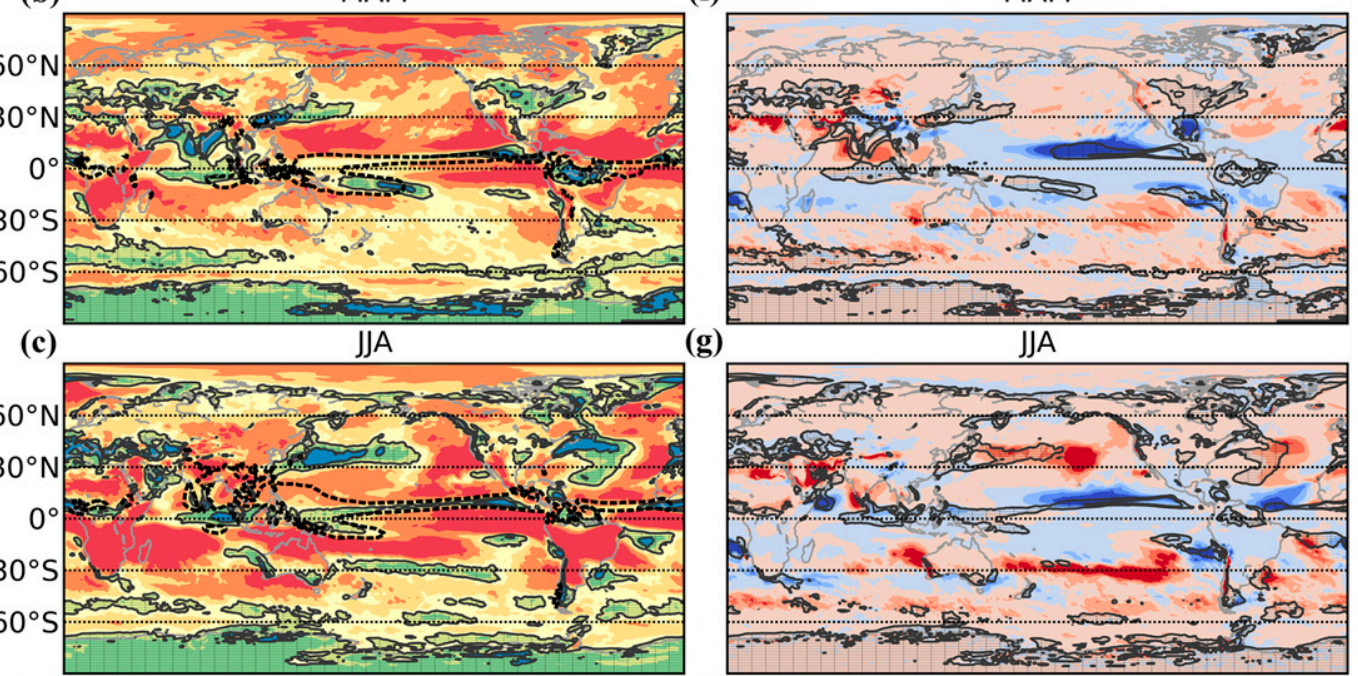

(g)
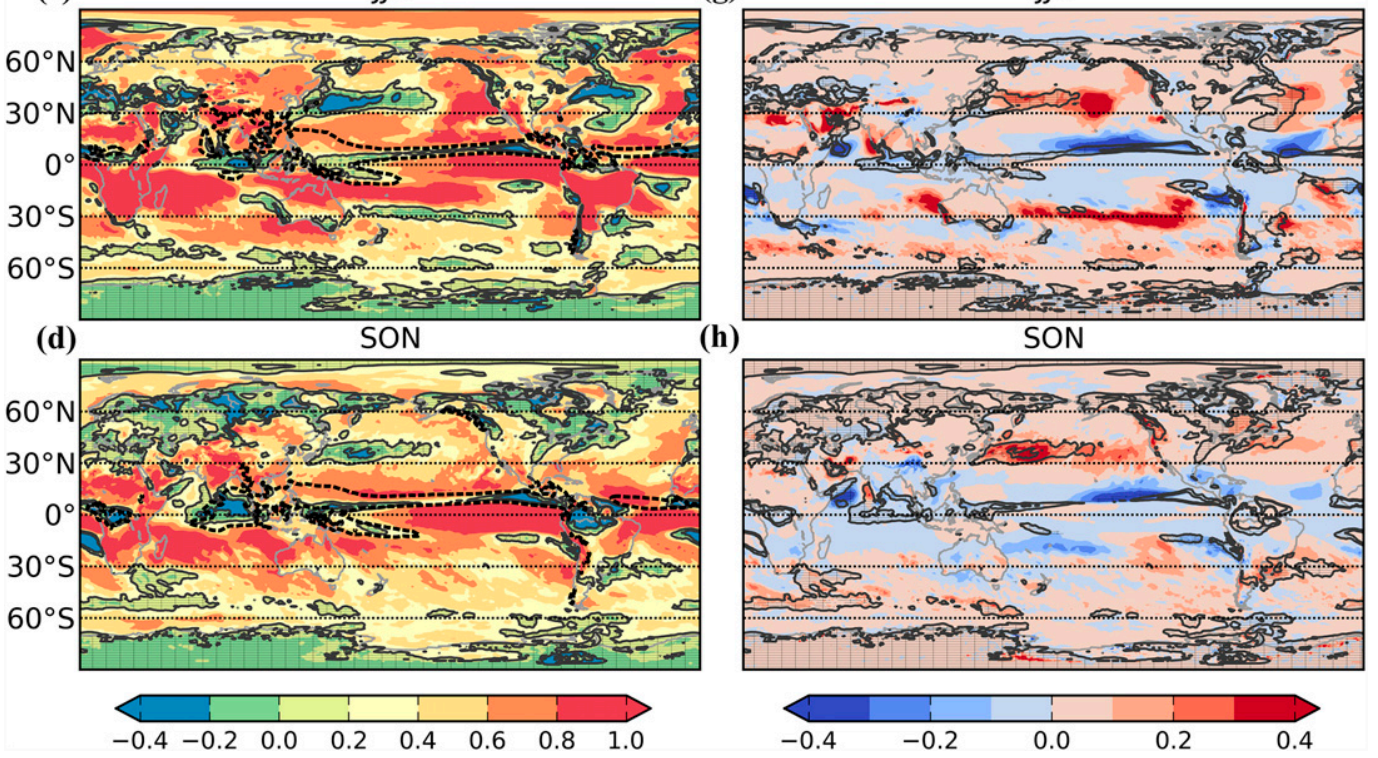

(h)

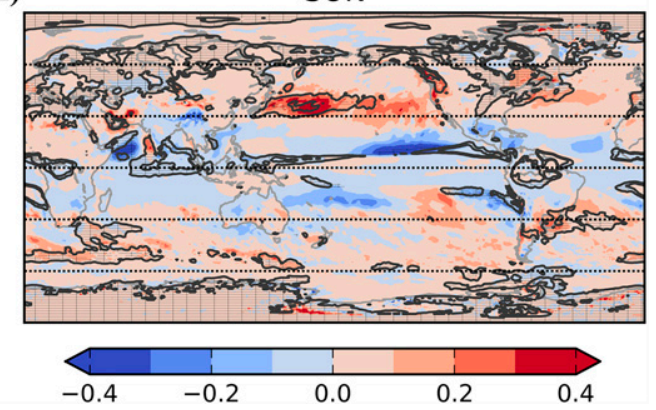

FIG. 3. The 37-yr-averaged correlation between CAPE and precipitation for (a) DJF, (b) MAM, (c) JJA, and (d) SON during 1979-2015. Black dashed contour encloses the areas with precipitation average $>8 \mathrm{~mm}_{\text {day }}{ }^{-1}$. Areas without the hatching indicate correlations between CAPE and precipitation that are significantly significant from zero at the 95\% confidence level. (e)-(h) As in (a)-(d), respectively, but for the correlation between SCAPE and precipitation minus the one between CAPE and precipitation. Areas without the hatching indicate correlations between SCAPE and precipitation that are statistically significant from zero at the $95 \%$ confidence level.

other hand, in regions with $f_{s}$ close to 1 , CSI dominates over conditional (static) instability, which is more favorable for pure slantwise convection.

Figures $4 \mathrm{a}-\mathrm{d}$ show the $37-\mathrm{yr}$ average of $f_{s}$ in four different seasons. Slantwise convection, in terms of $f_{s}$, is favored the most in the midlatitude western North Pacific with an averaged $f_{s}$ of above 0.7 in DJF. Note that while the average value is less than 1 , there are many instances when $f_{s}$ equals to 1 , especially in subtropical and midlatitude areas between $15^{\circ}$ and $45^{\circ} \mathrm{N}$ and between $15^{\circ}$ and $45^{\circ} \mathrm{S}$. In an environment where CSI and conditional (static) instability coexist (termed "convective symmetric instability;" i.e., CAPE > 0 and SCAPE > CAPE), mechanisms for the development of rainbands likely differ from pure upright or slantwise convection because the two types of instability may manifest on different scales and interact (Schultz and Schumacher 1999). The present climatology suggests that convective-symmetric instability, in 
TABLE 1. Correlation between SCAPE and precipitation and its difference from the correlation between CAPE and precipitation. Values averaged over different domains and for different seasons are also calculated. The averaged correlation coefficients between CAPE or SCAPE and precipitation (precip) are all statistically significant at the $95 \%$ confidence level for a two-tailed test.

\begin{tabular}{|c|c|c|c|c|c|c|c|c|c|c|}
\hline & \multicolumn{5}{|c|}{ Corr (SCAPE, precip) } & \multicolumn{5}{|c|}{ Corr (SCAPE, precip) - Corr (CAPE, precip) } \\
\hline & Annual & DJF & MAM & JJA & SON & Annual & DJF & MAM & JJA & SON \\
\hline Globe & 0.42 & 0.47 & 0.44 & 0.43 & 0.37 & 0.02 & 0.03 & 0.01 & 0.02 & 0.02 \\
\hline Tropics $\left(20^{\circ} \mathrm{N}-20^{\circ} \mathrm{S}\right)$ & 0.53 & 0.55 & 0.51 & 0.57 & 0.52 & -0.03 & -0.03 & -0.04 & -0.03 & -0.03 \\
\hline Subtropics midlatitudes $\left(20^{\circ}-60^{\circ}\right)$ & 0.46 & 0.49 & 0.46 & 0.48 & 0.44 & 0.06 & 0.08 & 0.04 & 0.06 & 0.05 \\
\hline Land & 0.34 & 0.44 & 0.33 & 0.37 & 0.25 & 0.02 & 0.02 & 0.02 & 0.02 & 0.02 \\
\hline North Pacific Ocean & 0.51 & 0.58 & 0.53 & 0.48 & 0.50 & 0.02 & 0.07 & -0.04 & 0.01 & 0.02 \\
\hline North Atlantic Ocean & 0.52 & 0.54 & 0.63 & 0.48 & 0.50 & 0.04 & 0.06 & 0.02 & 0.01 & 0.03 \\
\hline South Pacific Ocean & 0.47 & 0.42 & 0.45 & 0.53 & 0.53 & 0.03 & 0.02 & 0.01 & 0.05 & 0.01 \\
\hline South Atlantic Ocean & 0.42 & 0.36 & 0.43 & 0.44 & 0.44 & 0.03 & 0.03 & 0.03 & 0.04 & 0.03 \\
\hline Indian Ocean & 0.47 & 0.53 & 0.39 & 0.53 & 0.44 & 0.03 & 0.04 & 0.03 & 0.03 & 0.01 \\
\hline
\end{tabular}

terms of intermediate values for $f_{s}$, is rather common in subtropical and midlatitude areas.

Over much of the globe, the distribution of $f_{s}$ generally follows the distribution of the vertical wind shear (Figs. $4 \mathrm{e}-\mathrm{h}$ ), indicating that slantwise convection is more likely to occur in areas where vertical wind shear, and thus horizontal baroclinicity (via thermal wind balance outside the equatorial region) is stronger. However, $f_{s}$ is much smaller over land than over ocean even with strong vertical wind shear (e.g., over eastern Asia in DJF as well as over Australia in JJA). This finding arises in part because both SCAPE and CAPE are small there due to limited moisture content over land, particularly over complex terrain, during the winter season. Compared to the distribution of $\gamma_{s}$, the peak $f_{s}$ shifts slightly toward higher latitudes. This is because CAPE (and thus SCAPE) is generally larger in lower-latitude regions, which increases the denominator of Eq. (6) and thus reduces $f_{s}$. Recall that SCAPE is composed of both a static and symmetric term [see Eq. (3)], hence, in areas with moderate $\gamma_{s}$ and relatively large SCAPE, the symmetric term resulting from baroclinicity is still small relative to the static term (i.e., small $f_{s}$ ). Such areas are thus more likely to experience upright convection rather than slantwise convection (e.g., the Indian Ocean in JJA and the southeastern part of the North Pacific in DJF; Figs. 1e,g and 4a,c).

\section{2) VRS}

Figures 5a-d illustrate the global 30-yr-averaged VRS and frequency of its occurrence for four different seasons. The average is conditional upon the VRS being greater than zero (i.e., it omits instances of zero VRS) and the frequency is defined by the cumulative duration when VRS $>0$ divided by the total time. On the longterm average, the releasable moist symmetric instability generally has a continuous depth of $80-110 \mathrm{hPa}$ in the subtropics and midlatitudes. The spatial patterns of both the averaged VRS and the VRS frequency of occurrence show high similarities to those shown in G17 over the North Atlantic and European region. Large long-termaveraged VRS of above $110 \mathrm{hPa}$ in depth are observed over the westernmost North Pacific and North Atlantic Oceans, the Rocky Mountains, and the southeastern part of the North Atlantic Ocean in DJF (Fig. 5a) and over Asia and along $30^{\circ} \mathrm{S}$ of the South Pacific Ocean in JJA (Fig. 5c). Generally, the bottom of the VRS layer lies at a lower height over the ocean $(850-700 \mathrm{hPa})$ than over terrain $(\sim 600 \mathrm{hPa})$ in the midlatitudes (Figs. $5 \mathrm{e}-\mathrm{h})$.

The frequency of VRS occurrence agrees well with the distribution of $f_{s}$, and both resemble the climatological midlatitude storm tracks [e.g., Figs. 2a and 4a in Bengtsson et al. (2006); Fig. 1 in Tamarin and Kaspi (2017)]. This finding is consistent with G17's result for the North Atlantic. For the Northern Hemisphere, VRS more frequently occurs in the oceanic region downstream of the continents under midlatitude westerlies, such as over the northwestern Pacific and northwestern Atlantic with a peak frequency of over $15 \%$ and about $10 \%$, respectively, of the total time in DJF. Note that our value over the North Atlantic is somewhat smaller than the $\sim 20 \%$ shown in G17. As for the Southern Hemisphere, the VRS frequency distribution between $10^{\circ}$ and $40^{\circ} \mathrm{S}$ is more zonally symmetric as a result of the larger coverage of ocean than in the Northern Hemisphere. In all, regions with large VRS and high frequency of occurrence, such as the northwestern Pacific and northwestern Atlantic during DJF, March-May (MAM), and September-November (SON), as well as the midlatitude South Pacific and Atlantic in JJA, represent favorable environments for moist slantwise convection.

As mentioned in section $2 \mathrm{a}(2)$, CSI is more likely to exist in environments with strong wind shear and weak static stability, the combination of which tends to yield strong baroclinic instability. Thus, we also examine the climatology of the maximum Eady growth rate (Eady 1949): 

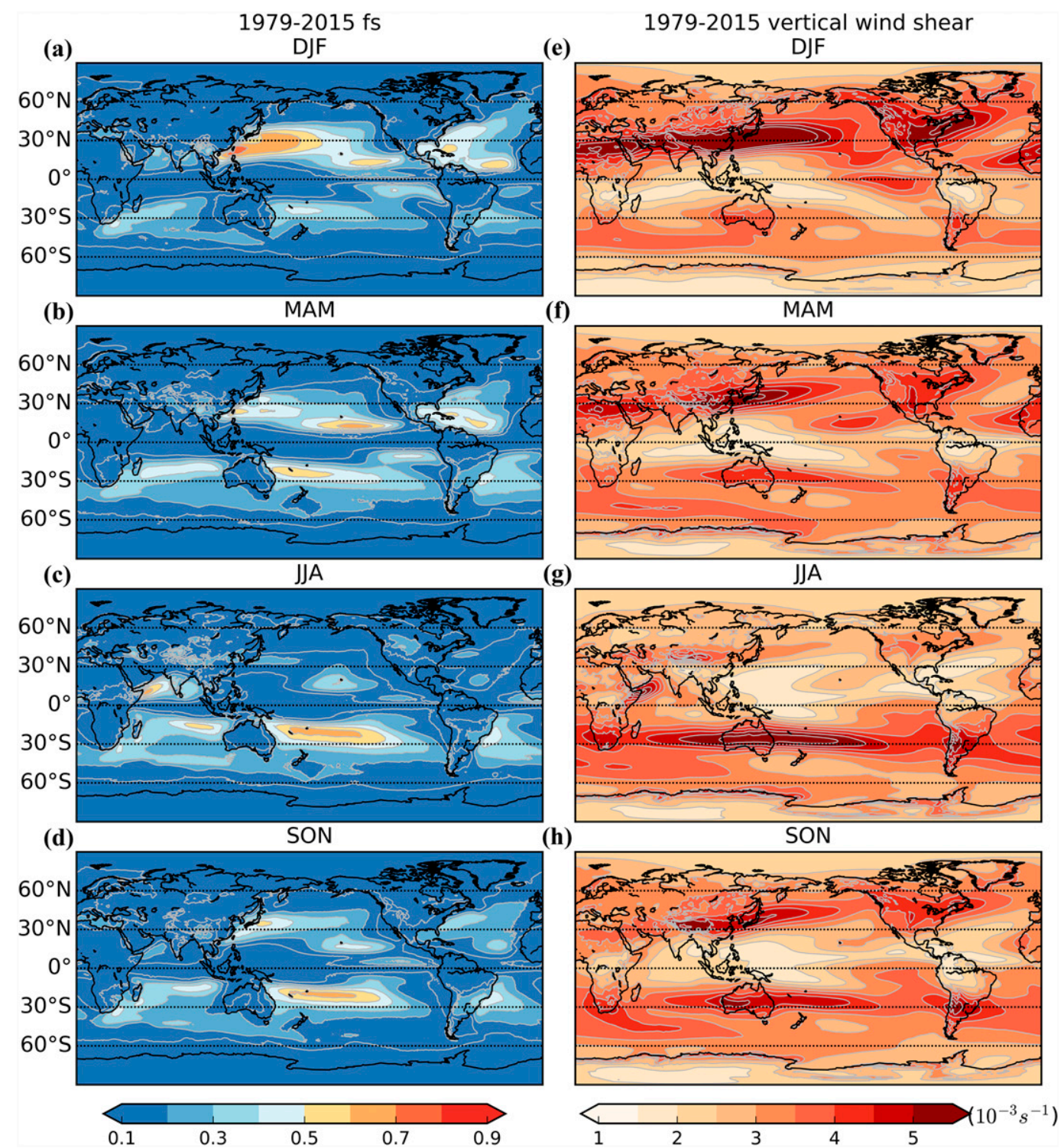

FIG. 4. The 37-yr-averaged $f_{s}$ [see Eq. (6) in the text] for (a) DJF, (b) MAM, (c) JJA, and (d) SON during 19792015. (e)-(h) As in (a)-(d), respectively, but for the vertically averaged (pressure weighted) wind shear from 200 to $900 \mathrm{hPa}$ (or at the first level above the surface if the surface lies above $900 \mathrm{hPa}$ ).

$$
\sigma=0.31 \frac{|f|}{N}\left|\frac{\partial \mathbf{V}}{\partial z}\right|
$$

where $N$ is the dry Brunt-Väisälä frequency, and $\mathbf{V}$ is the horizontal wind vector. We calculate this quantity at each level and then obtain the pressure-weighted average from 200 to $900 \mathrm{hPa}$ (or, at the first level above the surface if the surface lies above $900 \mathrm{hPa}$ ). Indeed, the result shows that deep and/or frequent VRS (Figs. 5a-d) coincide with the areas of strongest baroclinic instability (Figs. 5e-h).

However, while the conditionally averaged VRS have comparable magnitudes over land and over ocean, it is found that the VRS frequency tends to be much lower over land than over the oceans even with a similar strength of the peak baroclinic instability (over 1 day $^{-1}$ ). To address this issue, all three components of VRS are investigated separately (Fig. 6). While the maximum continuous air depth of CSI is slightly larger in the western ocean basins than over the eastern part of continents, likely related to the stronger baroclinicity over western oceanic boundary currents, the overall distribution is more zonally symmetric than that for the other two components of VRS. The maximum continuous depths of the layers with $\mathrm{RH}>90 \%$ and positive vertical motion both exhibit much stronger land-ocean contrasts in every season. Layers above the midlatitude ocean with $\mathrm{RH}>90 \%$ 


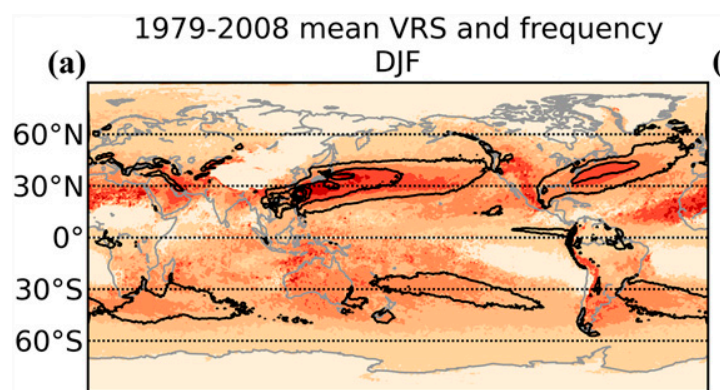

(b)

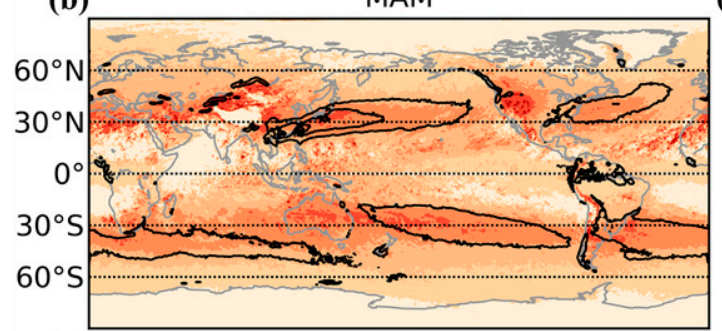

(c)

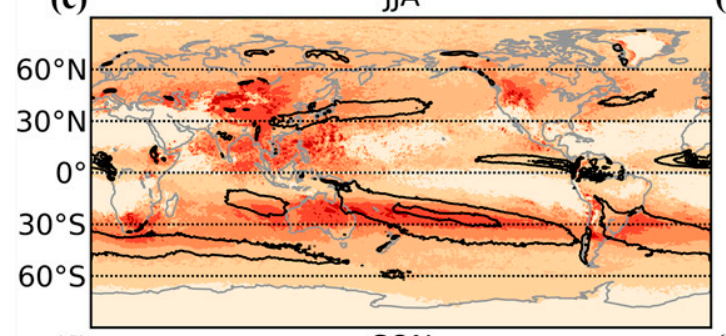

(d)

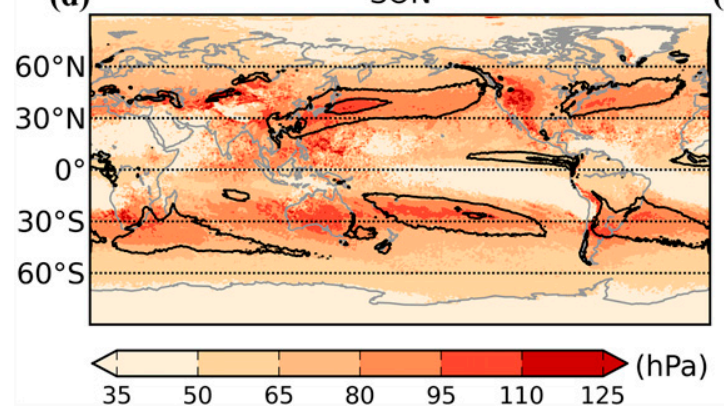

VRS bottom-level and Eady growth rate

(e)

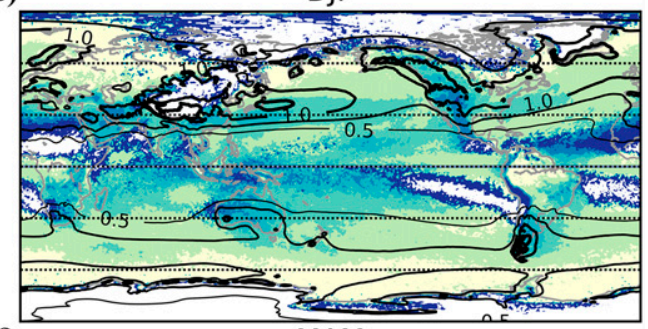

(f)

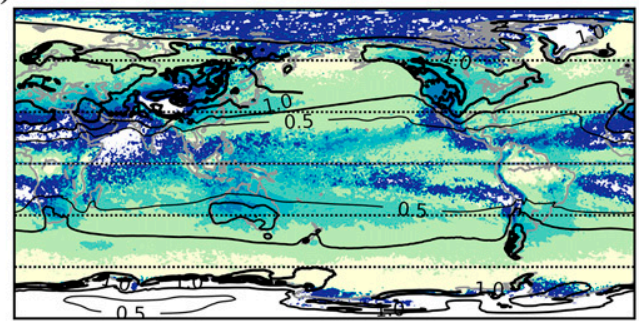

(g)

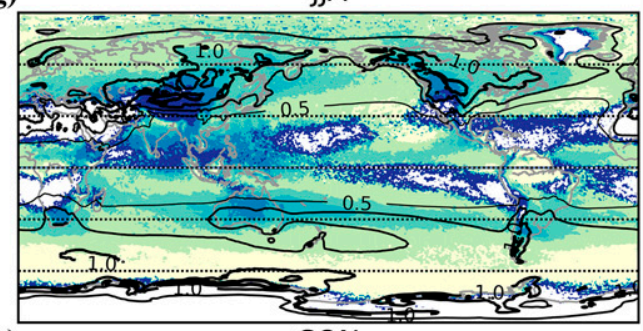

(h)

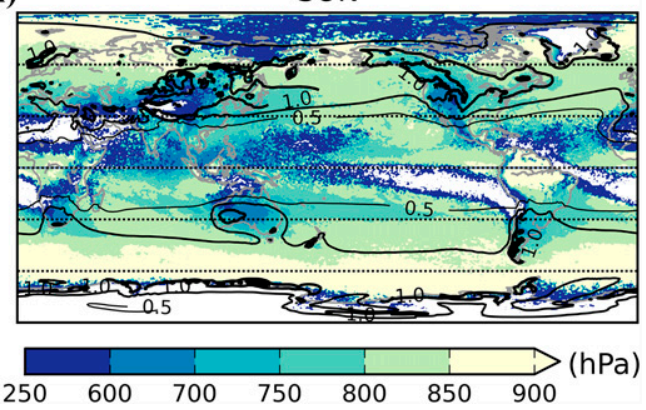

FIG. 5. The 30-yr-averaged VRS (shaded; hPa) and frequency of occurrence (contours; starting at $2 \%$; interval: 4\%) for (a) DJF, (b) MAM, (c) JJA, and (d) SON during 1979-2008. The average is made only when VRS is greater than zero. (e)-(h) As in (a)-(d), respectively, but for the bottom level of VRS (shaded; hPa) where VRS $>0$ and the vertically averaged (pressure weighted) maximum Eady growth rate from 200 to $900 \mathrm{hPa}$ or near the surface (contours; starting at 0.5 day $^{-1}$; interval: 0.25 day $^{-1}$ ).

are generally deeper than those above the adjacent midlatitude land, by around $50 \mathrm{hPa}$. Except for the ITCZ area, where upright convection is dominant, the vertical motion over the ocean is also deeper ( $>50 \mathrm{hPa}$ in depth) than that over adjacent land. Two additional calculations of VRS are conducted, each of which excludes the criteria of RH $>90 \%$ or upward motion (not shown). It is found that the maximum continuous depth where only CSI and $\mathrm{RH}>90 \%$ are considered (regardless of the presence of upward motion) shows higher resemblance to our original definition of VRS, suggesting that given the existence of CSI, the long-standing, vertically extended moisture over the ocean likely plays a decisive role in promoting the frequent existence of VRS there.

\section{d. Instantaneous features of slantwise convection events}

Detailed examination shows that, instantaneously, positive VRS is manifested as mesoscale cellular clusters or curved bands propagating eastward with a maximum 

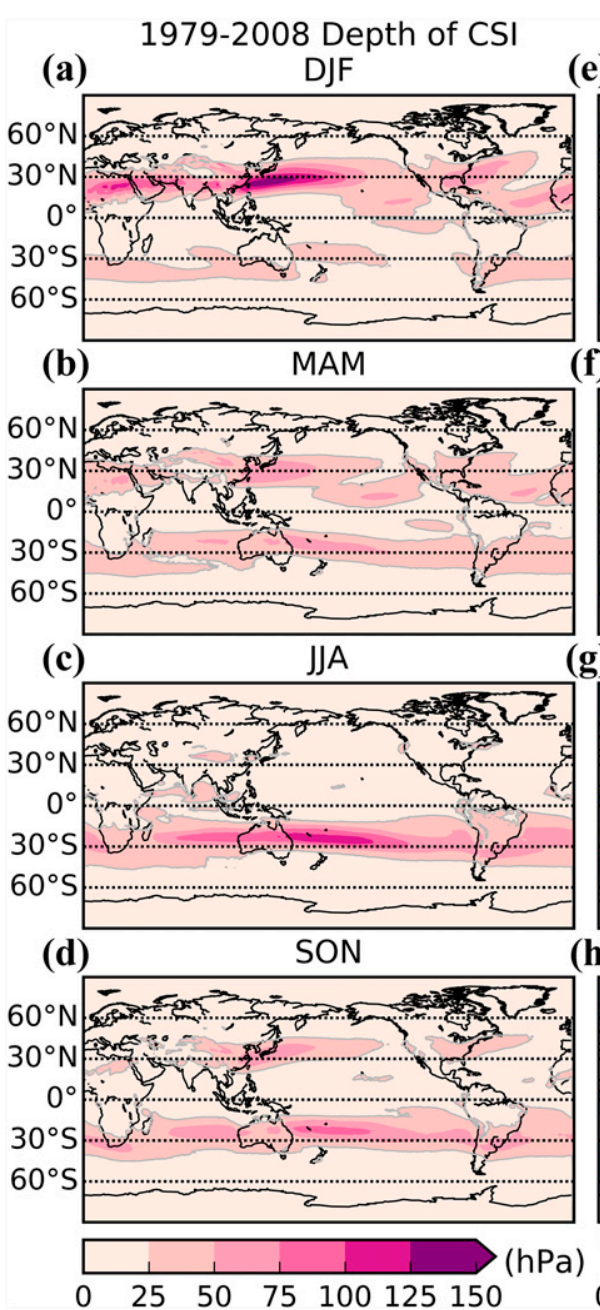

Depth of $\mathrm{RH}>90 \%$

(e)

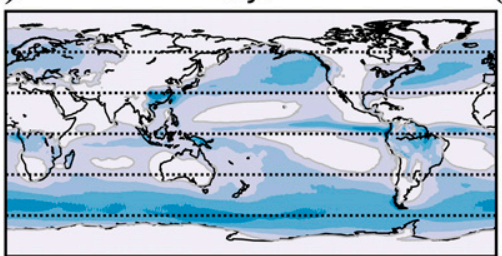

(f)

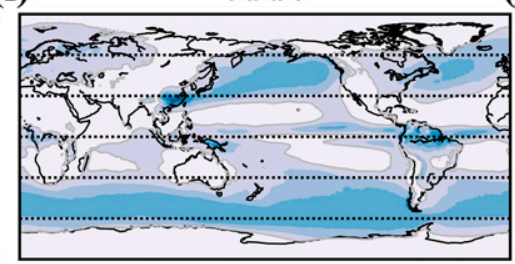

(g)

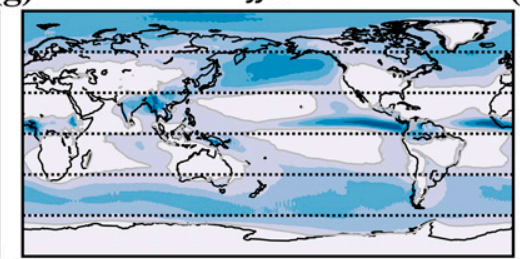

(h)

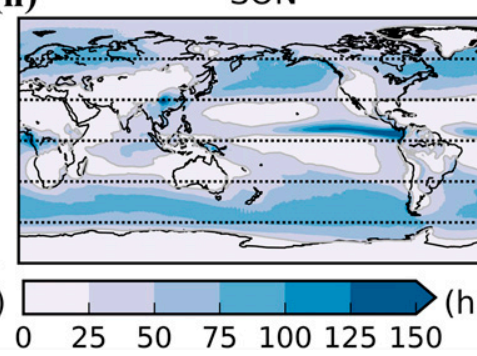

(i)

\section{Depth of upward motion DJF}

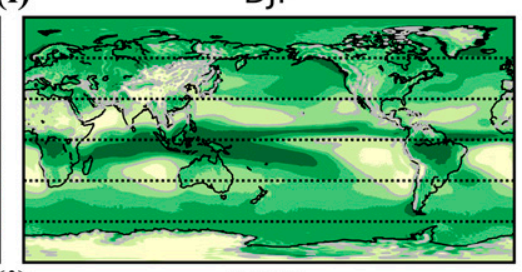

(j)

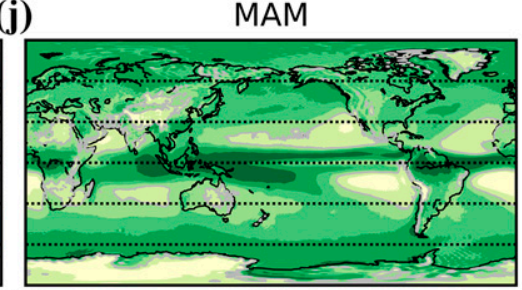

(k)

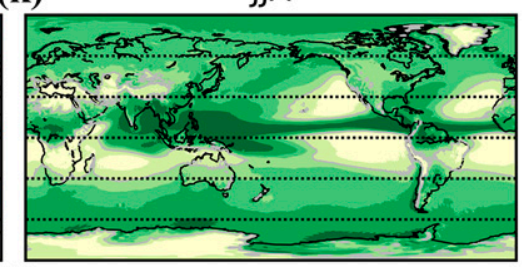

(I)

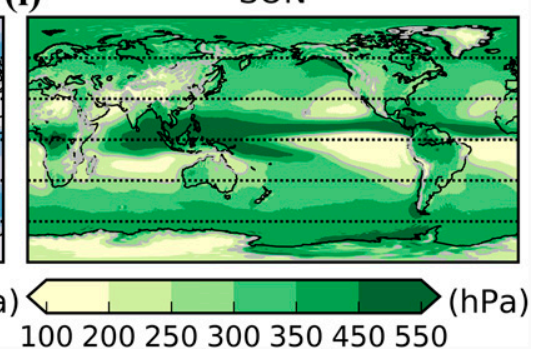

FIG. 6. The 30-yr-averaged maximum continuous air depth of the existence of CSI (shaded; hPa) for (a) DJF, (b) MAM, (c) JJA, and (d) SON during 1979-2008. (e)-(h) As in (a)-(d), respectively, but for the depth of RH > 90\% (shaded; hPa). (i)-(l) As in (a)-(d), respectively, but for the depth of upward motion (shaded; $\mathrm{hPa}$ ).

horizontal length scale of order $1000 \mathrm{~km}$ and a peak depth of around $350 \mathrm{hPa}$. To look more closely at the detailed distribution of $f_{s}$ and VRS for individual events, three observational cases associated with slantwise convection (Emanuel 1983b; Reuter and Yau 1990; G17) are briefly revisited here (Fig. 7). Although $f_{s}$ and VRS do not necessarily overlap with each other at any given instant, they both correspond well to the regions where moderate or heavy precipitation occurred along/near the fronts. The location of fronts generally coincides with the areas of heaviest precipitation and horizontal wind shifts, with the warm fronts extending eastward of the surface low and the cold fronts extending south-southwestward. As shown here, although the distribution of these two parameters within a given cyclone is case dependent, both the warm front [Figs. 7b,c; see Figs. 11 and 12 in Reuter and Yau (1990)] and the cold front [Figs. 7a,c; see Fig. 3a in Emanuel (1983b) and Fig. 2 in G17] are possible areas for slantwise convection. Interested readers can refer to the above-cited studies for the detailed discussion on the distribution of slantwise convection over the warm and/or cold frontal areas (in particular, G17 examined seven cases and presented the synthesis in schematic form in their Fig. 3).

\section{e. Correlation of VRS and cyclone activity}

The high resemblance between cyclone tracks (Figs. 8a-d) and VRS (Figs. 5a-d) motivates a quantification of the correlation between the two (Figs. 8e-h). This comparison focuses on the Northern Hemisphere where the cyclone data (Serreze 2009) are available. The general seasonal variation of cyclone frequency broadly agrees with that of VRS occurrence frequency, with a highest maximum value of 3.2 month $^{-1}$ in both the North Pacific and North 

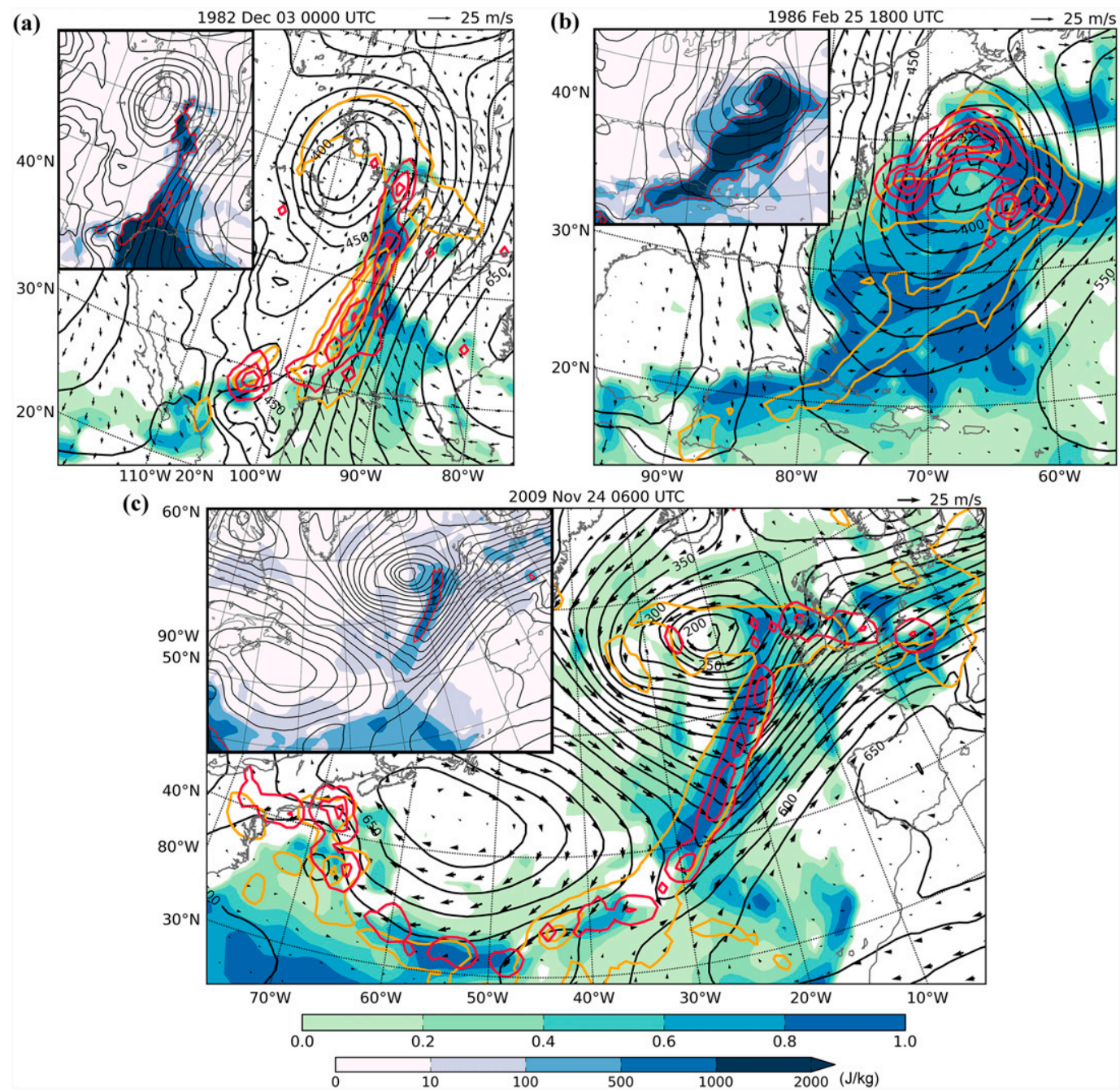

FIG. 7. Snapshots of slantwise convection cases analyzed in (a) Emanuel (1983b), (b) Reuter and Yau (1990), and (c) G17. SCAPE (shaded in the inset panels; $\mathrm{J} \mathrm{kg}^{-1}$ ) and $f_{s}$ (shaded in the main panels), ERA-Interim 6-h accumulated precipitation (yellow contours; starting at $2 \mathrm{~mm}$; interval: $10 \mathrm{~mm}$ ), VRS (red contours in the main panels; starting at $10 \mathrm{hPa}$; interval: $50 \mathrm{hPa}$ ), and $950-\mathrm{hPa}$ wind (vectors; $\mathrm{m} \mathrm{s}^{-1}$ ) and geopotential height (black contours; $\mathrm{m}$ ). The red contours in the inset panels bounds where SCAPE is $400 \mathrm{~J} \mathrm{~kg}^{-1}$ larger than CAPE.

Atlantic basins in DJF and a lowest maximum frequency of around 2 month $^{-1}$ over these same regions in JJA. The correlation between VRS and cyclone frequency is calculated using their monthly averages from January 1979 to December 2008. Figures 8e-h show that the correlation coefficient between VRS and cyclone frequency is generally positive over the entire Northern Hemisphere with a rather small domain average of 0.09 , and among all the seasons, DJF and JJA feature relatively higher correlation coefficients of 0.12 and 0.17 , respectively (Table 2). The other domain-averaged correlation coefficients during different seasons are summarized in Table 2. Locally, relatively high correlation coefficients of above 0.6 can be observed in regions where cyclones are less frequent (e.g., the eastern coast of northeastern Asia in DJF and the Middle East, the eastern North Pacific Ocean, and the southern North Atlantic Ocean in JJA). Although the null hypothesis of zero correlation cannot be ruled out at the $95 \%$ confidence level, the general positive correlation coefficient suggests that moist slantwise convection has a higher (lower) occurrence over the areas with more (less) cyclone activity and where the background baroclinic instability is stronger (weaker).

A related question that merits exploration is how often are cyclones associated with slantwise convection? We calculate the observed numbers of cyclones that contain nonzero VRS within a $300-\mathrm{km}$ radius of a cyclone center and divided them by the total observational 

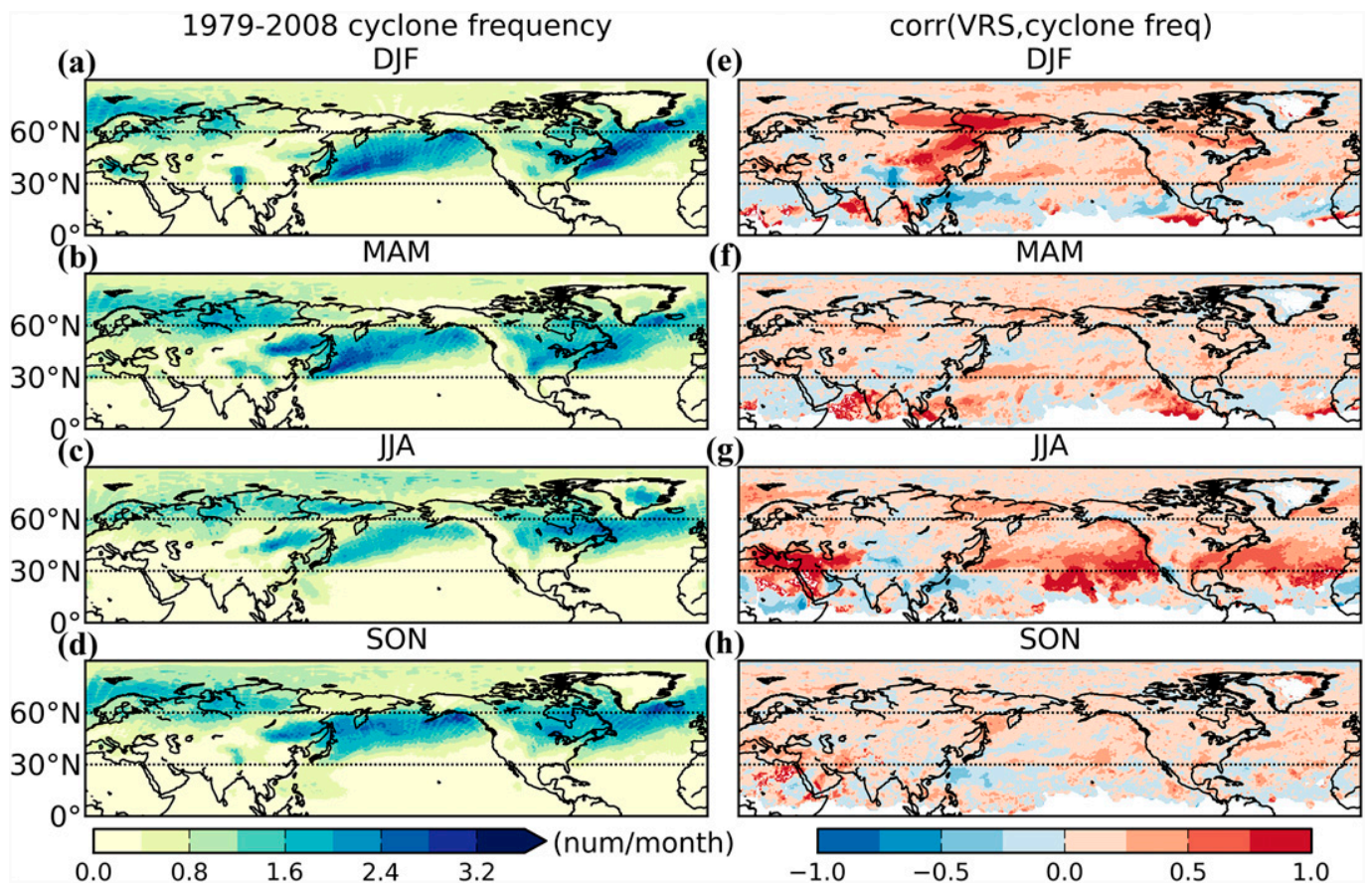

FIG. 8. The 30-yr-averaged cyclone frequency (shaded; month ${ }^{-1}$ ) for (a) DJF, (b) MAM, (c) JJA, and (d) SON during 1979-2008. (e)-(h) As in (a)-(d), respectively, but for the correlation between VRS and cyclone frequency. The blank areas are where the standard deviation of either VRS or cyclone frequency equals zero.

number of cyclones [note for a cyclone with a lifetime of 5 days, the observational number is $5 \times 4$ (4 observations per day $)=20$ instead of 1 ], which gives a $30 \%$ probability of CSI release (VRS $>0$ ) given the existence of a cyclone. In other words, at a given time, $30 \%$ of the observed cyclones are likely exhibiting slantwise convection near their core. Considering that slantwise convection may not exist for the whole life cycle of each cyclone, the calculation is further partitioned into different categories based on the observed intensification rate of the cyclones for each time step. Despite the increasing margin of error (yet still small with values $<1.2 \%$ ) due to decreasing sample size, the probability of VRS $>0$ increases with the intensification rate of the cyclones (Fig. 9). While the chance for cyclones in the weakening stage to exhibit slantwise convection is less than $30 \%$, cyclones undergoing rapid intensification (central pressure drops equal to or more than $24 \mathrm{hPa}$ day $^{-1}$ ) have a greater than $57 \%$ chance of being associated with slantwise convection.

\section{f. Time evolution of CSI within explosive and nonexplosive cyclones}

It was just shown that the susceptibility of the atmosphere to slantwise convection exhibits a strong relationship to the intensification rate of the cyclone. To further investigate this issue, the averaged time evolutions of SCAPE, CAPE, and VRS around the center of the cyclones from 1979 to 2008 are presented in Fig. 10, along with the averaged intensity change of the cyclones. The analysis is conducted separately for explosive and nonexplosive cyclones, and a comparison between them is then performed.

For each cyclone that underwent explosive development during its lifetime, the onset of the rapid intensification is identified as $0 \mathrm{~h}$, and then the associated SCAPE, CAPE, and VRS at different times (with an interval of $6 \mathrm{~h}$ ) are calculated by averaging over a circular domain with a radius of $300 \mathrm{~km}$ around the cyclone center. As shown in Fig. 10b, slight buildups of SCAPE and VRS are observed $36-12 \mathrm{~h}$ before the onset, which are followed by significant drops during the rapid deepening stage. As cyclones reach their peak intensity (at $+30 \mathrm{~h}$ in Fig. 10a), the two values decrease to a minimum and remain low for the following $30 \mathrm{~h}$. Note that the buildup and the drop of VRS slightly lag those of SCAPE, suggesting that the environment first becomes thermodynamically susceptible to CSI, and a few hours later the layers with releasable CSI develop and/or deepen (thus increasing VRS) because of intensifying vertical motion. The evolution of CAPE, on the other hand, does not show such a strong sensitivity to the phase of cyclone evolution.

The standard deviations of both SCAPE and VRS are even larger than their averaged values, indicating a large uncertainty among different explosive cases. Such a large 
TABLE 2. Correlation coefficients between VRS and cyclone frequency for different domains and different seasons during January 1979-December 2008. Boldface values are statistically significant at the $95 \%$ confidence level for a two-tailed test.

\begin{tabular}{lccccc}
\hline \hline & Annual & DJF & MAM & JJA & SON \\
\hline Northern Hemisphere & 0.09 & 0.12 & 0.10 & 0.17 & 0.09 \\
Tropics & 0.03 & 0.06 & 0.19 & 0.04 & 0.07 \\
Subtropics and midlatitudes & $\mathbf{0 . 1 1}$ & 0.12 & 0.09 & $\mathbf{0 . 2 5}$ & 0.10 \\
Land & 0.08 & 0.17 & 0.08 & 0.13 & 0.10 \\
North Pacific Ocean & 0.10 & 0.07 & 0.14 & $\mathbf{0 . 2 5}$ & 0.07 \\
North Atlantic Ocean & $\mathbf{0 . 1 0}$ & 0.08 & 0.09 & $\mathbf{0 . 2 7}$ & 0.10 \\
\hline
\end{tabular}

variability is expected given the large variability in the sizes and the structures of cyclones and the different synoptic environments of the different cases. Nevertheless, the mean evolution of these indices provides a general picture that the cyclones become increasingly symmetrically unstable prior to their rapid intensification and then release this instability during the rapid deepening phase through vigorous slantwise convection. By the time that peak intensity is reached, the likelihood of slantwise convection drops to a minimum as the atmosphere is almost fully neutralized to slantwise displacements. This averaged evolution is consistent with that found in several observational case studies (e.g., Emanuel 1983b; Shutts 1990a,b; Reuter and Yau 1993), providing support that a slantwise moist adjustment takes place within explosive cyclones, especially during their intensifying stage.

The time evolutions of SCAPE, CAPE, and VRS for nonexplosive cyclones in Fig. 10e show that, unlike in the explosive cases, all three indices exhibit a gradual decrease before these cyclones reach their peak intensity, and the rate of decrease becomes even smaller thereafter. After the intensification of the cyclone, VRS reduces to as low a value as that in explosive cases but SCAPE and CAPE do not reduce as much, suggesting that the maximum available energy is not entirely released, possibly because of the lack of deep-layer humidity and/or large-scale ascent in nonexplosive cases. Also, despite large standard deviations, the magnitudes of SCAPE and VRS (but not CAPE) are smaller than those observed in explosive cases on average.

Considering slantwise convection can occur along the cold-frontal system that extends farther away from the center, a sensitivity test on the selected radius, ranging from 300 to $1200 \mathrm{~km}$, is conducted (Figs. 10c,f). While the averaged values of these indices decrease with selected radius, their overall trends do not change significantly.

The contrasting evolution of these indices between explosive and nonexplosive cases indicates that the intensity of slantwise convection may vary strongly with the cyclone intensification rate. During the deepening period, explosive cyclones tend to have more active (with larger

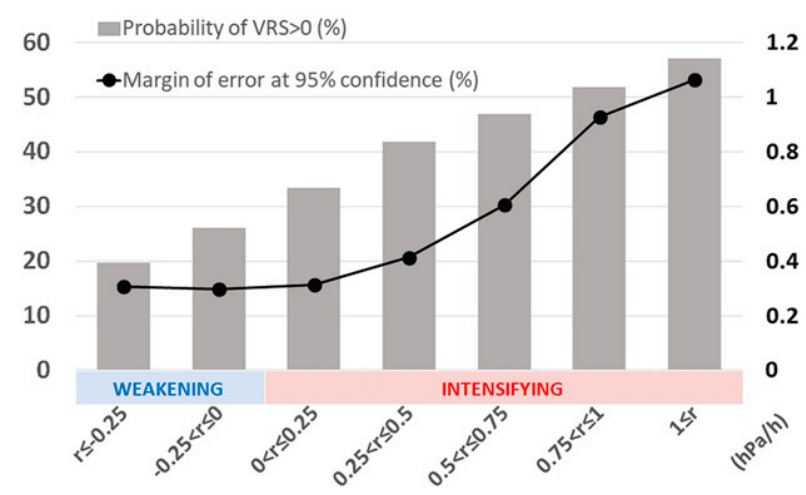

FIG. 9. Probability of slantwise convection occurrence potential given the existence of cyclones with different intensification rates $r$, defined by the decrease of central pressure per hour. Positive (negative) values $\langle r\rangle$ indicate the cyclones are undergoing intensification (weakening) at that time. The black curve (corresponding to the value on the right $y$ axis) is the margin of error at the $95 \%$ confidence level (\%).

decrease of SCAPE but not CAPE) and deeper (with larger VRS) slantwise convection than nonexplosive cases, and the associated enhancement of latent heat release lends support to the notion that slantwise convection can promote an intensification of the cyclones. Furthermore, the increasing slantwise convection potential at early stages in explosive cyclones may play a key role in determining whether rapid intensification subsequently occurs. The potentially important role of slantwise convection on the life cycle of explosive cyclones suggested by this analysis is a topic that merits further investigation.

\section{Summary}

The purpose of this study is to understand the climatology of slantwise convection over the entire globe, which has not been extensively presented in the literature. Two indices, slantwise convective available potential energy (SCAPE) and vertically integrated extent of realizable symmetric instability (VRS), are calculated to assess the climatology of conditional symmetric instability using the 37-yr ERA-Interim dataset. Furthermore, the correlation of the slantwise convection potential and properties of observed weather systems, such as precipitation and cyclone activity, are also investigated statistically.

The spatial distribution of the 37-yr seasonal-averaged SCAPE, and the seasonal variation of its zonal average, are similar to those of CAPE except for a wider northsouth extent. CAPE has been widely used as a diagnostic tool for assessment of the potential for deep convection (e.g., Brooks et al. 2003; Marsh et al. 2007; Subrahmanyam et al. 2015). G17 showed that the correlations of SCAPE with precipitation generally exceed those of CAPE with precipitation over subtropical and midlatitude areas in the 

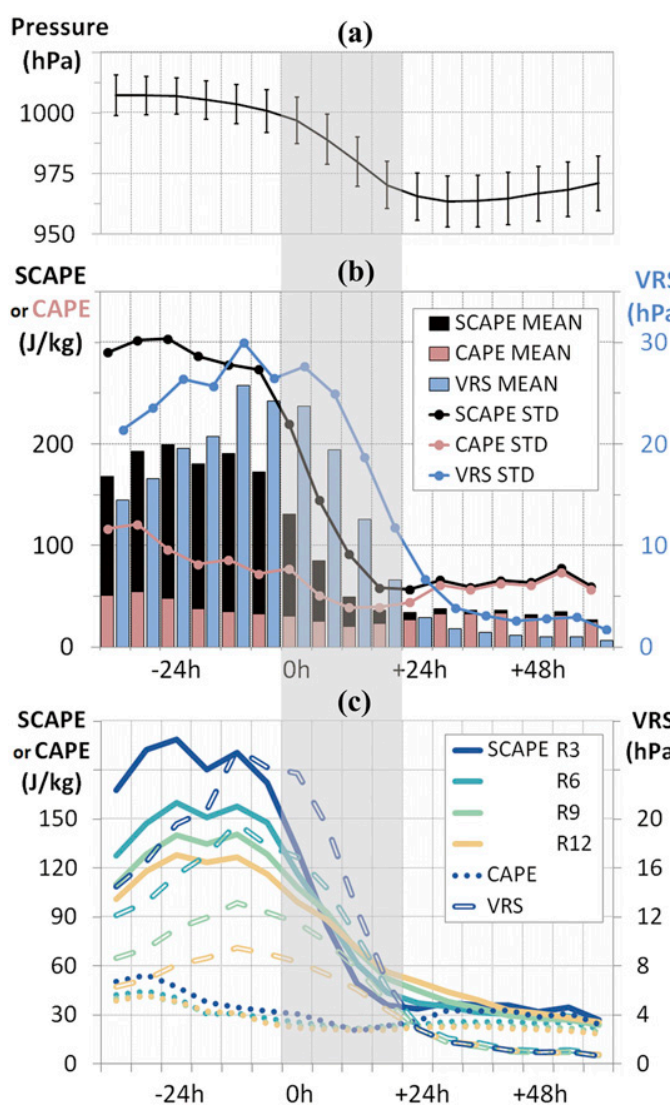

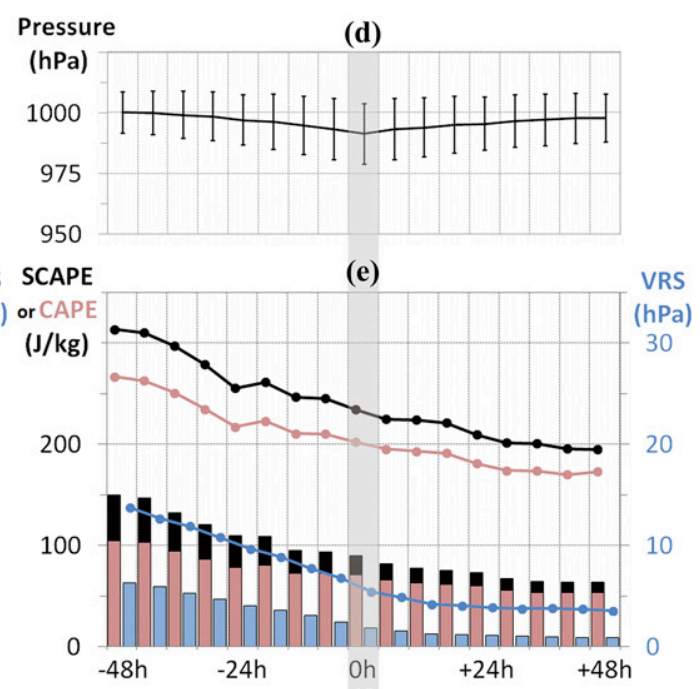

(f)

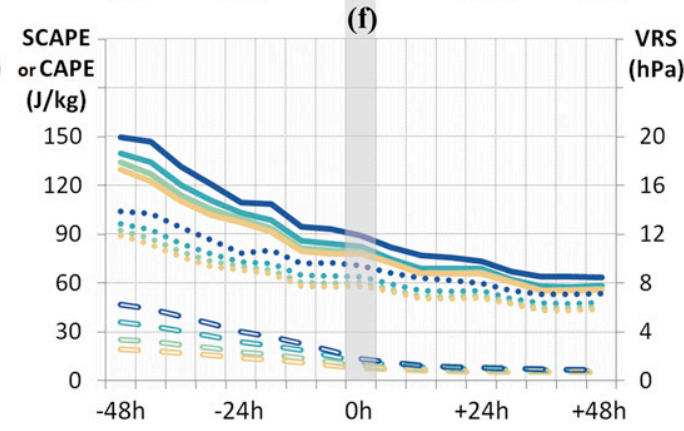

FIG. 10. (a) Averaged time evolution of central sea surface pressure (curve and error bars denote the standard deviation among all the cases); (b) SCAPE (black bars), CAPE (pink bars), and VRS (blue bars) averaged within a radius of $300 \mathrm{~km}$ around each center of explosive cyclones in the Northern Hemisphere during 1979-2008. Standard deviation for SCAPE and VRS among all the cases are denoted in dash-dotted curves. (c) Averaged SCAPE (solid), CAPE (dotted), and VRS (dashed) using different selected radii ranging from $300 \mathrm{~km}$ (R3) to $1200 \mathrm{~km}$ (R12). The gray shading denotes the period of rapid intensification (RI) and $0 \mathrm{~h}$ is defined as the onset of the RI in each cyclone. (d)-(f) As in (a)-(c), respectively, but for nonexplosive cyclones, and $0 \mathrm{~h}$ is defined as the time while reaching the peak intensity.

North Atlantic and European regions. This study extends a similar analysis to the whole globe, verifying that, in general, SCAPE correlates with precipitation more strongly than CAPE in a climatological content since it accommodates both upright convection and slantwise convection. Both CAPE and SCAPE feature statistically significant domain-averaged correlation coefficients of around 0.4-0.5 with precipitation. Generally, SCAPE exhibits a higher correlation with precipitation than CAPE, in particular over subtropical and midlatitude areas with a 0.06-higher domain-averaged correlation coefficient annually. Locally, SCAPE has $>0.3$-higher correlation coefficients with precipitation than CAPE in the North Pacific and North Atlantic basins during December-February (DJF), indicating the importance of slantwise convection to precipitation there. In contrast, SCAPE shows a lower correlation with precipitation than does CAPE in some tropical regions, possibly because upright convection is still dominant in areas of large CAPE. Furthermore, thermal wind balance is not valid in the tropics and thus slantwise convection is less likely to be relevant there considering the theoretically 2D nature of symmetric instability.

Compared to the absolute difference of SCAPE and CAPE, the fractional residual term, $f_{s}=$ (SCAPE CAPE)/SCAPE, helps more clearly to identify the relative importance of upright convection and slantwise convection. Tropical areas are dominated by upright convection (with $f_{s}$ near zero) in almost every season. By contrast, there is a high chance of the coexistence of upright and slantwise convection (with intermediate values of $f_{s}$ ) in subtropical and midlatitude regions. Areas of strong vertical wind shear, such as over the midlatitude western oceanic boundary currents, favor slantwise convection (with higher $f_{s}$ ). In particular, the northwestern Pacific Ocean and the $10^{\circ}-30^{\circ} \mathrm{S}$ band of the South Pacific Ocean exhibit the highest likelihoods of 
pure slantwise convection in terms of $f_{s}$ in DJF and in June-August (JJA), respectively.

Another index for the assessment of releasable conditional symmetric instability, VRS, is also examined and extended globally to provide a complementary perspective of moist slantwise convective potential. Unlike SCAPE, which encompasses both static and moist symmetric instability, the definition of VRS explicitly excludes static instability and thus only considers moist symmetric instability. Herein, the VRS is a measure of the maximum continuous air thickness where conditional symmetric instability, moisture, and vertical motion coexist. The climatological distributions of VRS frequency and $f_{s}$ share large similarities, specifically that the air over the midlatitude westernmost oceans (i.e., storm-track regions) is the most susceptible to slantwise convection due to strong baroclinicity, partly strengthened by the western oceanic boundary currents, and abundant moisture. The instantaneous VRS can exceed $350 \mathrm{hPa}$ and has a rather sparse horizontal distribution, manifesting either as cellular clusters or in bands stretching over several hundred kilometers, likely associated with frontal systems. The climatologically averaged depth of VRS peaks at $110 \mathrm{hPa}$, generally with the bottom level between 850 and $700 \mathrm{hPa}$. G17 observed a close correspondence of the VRS spatial structure with the North Atlantic storm track. Consistent with that result, the present study finds that the seasonal distribution of VRS frequency resembles the seasonal cyclone frequency in both the North Atlantic and North Pacific. Although the Northern Hemisphere-averaged correlation coefficient between VRS and cyclone frequency does not pass the $95 \%$ confidence level, the positive value of 0.11 averaged over subtropics and midlatitudes in the Northern Hemisphere is statistically significant. A novel finding of this study is that the probability of CSI release (VRS $>0$ ) is $30 \%$ given the existence of a cyclone and increases with the intensification rate of cyclones. A cyclone undergoing rapid intensification has a greater-than$57 \%$ chance of exhibiting slantwise convection.

Finally, the evolution of slantwise convection potential during the life cycles of explosive and nonexplosive cyclones has been investigated for the first time. A clear separation between explosive and nonexplosive cases was found. While for explosive cyclones, both VRS and SCAPE (but not CAPE) increase from 36 to $12 \mathrm{~h}$ prior to the onset of their rapid intensification and then decrease sharply thereafter, the nonexplosive cases exhibit a much gentler decreasing rate of VRS and SCAPE during the entire period of interest. Thus, not only does slantwise convection have a higher chance to occur in those explosive cases at the peak deepening stage, it is also expected to be more active (with a larger release of SCAPE but not CAPE) and deeper (with a larger VRS), which may contribute to the rapid intensification by releasing additional latent heat. After the cyclones reach their peak intensity, the atmosphere is modified to a nearly slantwise neutral state with low SCAPE-CAPE and VRS in both the explosive and nonexplosive cases.

Acknowledgments. The research reported here has been supported by the NSERC/Hydro-Quebec Industrial Research Chair program. We thank Morgan E. O'Neill, Suzanne Gray, and one anonymous reviewer for their valuable comments and suggestion that helped to improve this study.

\section{REFERENCES}

Adler, R. F., and Coauthors, 2003: The Version-2 Global Precipitation Climatology Project (GPCP) monthly precipitation analysis (1979-present). J. Hydrometeor., 4, 1147-1167, https://doi.org/ 10.1175/1525-7541(2003)004<1147:TVGPCP $>2.0 . C O ; 2$.

Balasubramanian, G., and M. K. Yau, 1994: Baroclinic instability in a two-layer model with parameterized slantwise convection. J. Atmos. Sci., 51, 971-990, https://doi.org/ 10.1175/1520-0469(1994)051<0971:BIIATL >2.0.CO;2.

Bengtsson, L., K. I. Hodges, and E. Roeckner, 2006: Storm tracks and climate change. J. Climate, 19, 3518-3543, https://doi.org/ 10.1175/JCLI3815.1.

Bennetts, D. A., and B. J. Hoskins, 1979: Conditional symmetric instability-A possible explanation for frontal rainbands. Quart. J. Roy. Meteor. Soc., 105, 945-962, https://doi.org/ 10.1002/qj.49710544615.

Bromwich, D. H., J. P. Nicolas, and A. J. Monaghan, 2011: An assessment of precipitation changes over Antarctica and the Southern Ocean since 1989 in contemporary global reanalyses. J. Climate, 24, 4189-4209, https://doi.org/10.1175/2011JCLI4074.1.

Brooks, H. E., J. W. Lee, and J. P. Craven, 2003: The spatial distribution of severe thunderstorm and tornado environments frim global reanalysis data. Atmos. Res., 67-68, 73-94, https:// doi.org/10.1016/S0169-8095(03)00045-0.

Dee, D. P., and Coauthors, 2011: The ERA-Interim reanalysis: Configuration and performance of the data assimilation system. Quart. J. Roy. Meteor. Soc., 137, 553-597, https://doi.org/ 10.1002/qj.828.

Dixon, R. S., K. A. Browning, and G. J. Shutts, 2002: The relation of moist symmetric instability and upper-level potential-vorticity anomalies to the observed evolution of cloud heads. Quart. J. Roy. Meteor. Soc., 128, 839-859, https://doi.org/10.1256/ 0035900021643719.

Eady, E. T., 1949: Long waves and cyclone waves. Tellus, 1, 33-52, https://doi.org/10.3402/tellusa.v1i3.8507.

Emanuel, K. A., 1983a: The Lagrangian parcel dynamics of moist symmetric instability. J. Atmos. Sci., 40, 2368-2376, https://doi.org/ 10.1175/1520-0469(1983)040<2368:TLPDOM >2.0.CO;2.

_ 1983b: On assessing local conditional symmetric instability from atmospheric soundings. Mon. Wea. Rev., 111, 2016-2033, https:// doi.org/10.1175/1520-0493(1983)111<2016:OALCSI >2.0.CO;2.

Glinton, M., 2013: The role of conditional symmetric instability in numerical weather prediction. Ph.D. thesis, University of Reading, 251 pp.

— S. L. Gray, J. M. Chagnon, and C. J. Morcrette, 2017: Modulation of precipitation by conditional symmetric 
instability release. Atmos. Res., 185, 186-201, https://doi.org/ 10.1016/j.atmosres.2016.10.013.

Gray, S. L., and A. J. Thorpe, 2001: Parcel theory in three dimensions and the calculation of SCAPE. Mon. Wea. Rev., 129, 1656-1672, https://doi.org/10.1175/1520-0493(2001)129<1656: PTITDA $>2.0 . \mathrm{CO} ; 2$.

_ , O. Martínez-Alvarado, L. H. Baker, and P. A. Clark, 2011: Conditional symmetric instability in sting-jet storms. Quart. J. Roy. Meteor. Soc., 137, 1482-1500, https://doi.org/10.1002/qj.859.

Hawcroft, M. K., L. C. Shaffrey, K. I. Hodges, and H. F. Dacre, 2016: Can climate models represent the precipitation associated with extratropical cyclones? Climate Dyn., 47, 679-695, https://doi.org/10.1007/s00382-015-2863-z.

Holton, J. R., 2004: An Introduction to Dynamic Meteorology. 4th ed. Elsevier, 535 pp.

Hoskins, B. J., 1974: The role of potential vorticity in symmetric stability and instability. Quart. J. Roy. Meteor. Soc., 100, 480482, https://doi.org/10.1002/qj.49710042520.

Huang, J., 1991: A numerical study of slantwise convection. M.S. thesis, Dept. of Meteorology, McGill University, 73 pp.

Kållberg, P. W., 2011: Forecast drift in ERA-Interim. ECMWF ERA Rep. Series 10, 11 pp., https://www.ecmwf.int/sites/default/files/ elibrary/2011/10381-forecast-drift-era-interim.pdf.

Korty, R. L., and T. Schneider, 2007: A climatology of the tropospheric thermal stratification using saturation potential vorticity. J. Climate, 20, 5977-5991, https://doi.org/10.1175/2007JCLI1788.1.

Kuo, Y.-H., M. A. Shapiro, and E. G. Donall, 1991: The interaction between baroclinic and diabatic processes in a numerical simulation of a rapidly intensifying extratropical marine cyclone. Mon. Wea. Rev., 119, 368-384, https://doi.org/10.1175/ 1520-0493(1991)119<0368:TIBBAD > 2.0.CO;2.

Ma, L., 2000: On the parameterization of slantwise convection in general circulation models. Ph.D. thesis, McGill University, 175 pp.

Markowski, P. M., and Y. Richardson, 2010: Mesoscale Meteorology in Midlatitudes. Wiley-Blackwell, 424 pp.

Marsh, P. T., H. E. Brooks, and D. J. Karoly, 2007: Assessment of the severe weather environment in North America simulated by a global climate model. Atmos. Sci. Lett., 8, 100-106, https:// doi.org/10.1002/asl.159.

Monkam, D., 2002: Convective available potential energy (CAPE) in northern Africa and tropical Atlantic and study of its connections with rainfall in central and West Africa during summer 1985. Atmos. Res., 62, 125-147, https://doi.org/10.1016/ S0169-8095(02)00006-6.

Morcrette, C. J., 2004: Radar and modelling studies of upright and slantwise convection. Ph.D. thesis, University of Reading, $172 \mathrm{pp}$.

O'Neill, M. E., and Y. Kaspi, 2016: Slantwise convection on fluid planets. Geophys. Res. Lett., 43, 10 611-10 620, https://doi.org/ 10.1002/2016GL071188.

Reuter, G. W., and M. K. Yau, 1990: Observations of slantwise convective instability in winter cyclones. Mon. Wea. Rev., 118, 447-458, https:// doi.org/10.1175/1520-0493(1990)118<0447:OOSCII>2.0.CO;2.

—, and —, 1993: Assessment of slantwise convection in ERICA cyclones. Mon. Wea. Rev., 121, 375-386, https://doi.org/ 10.1175/1520-0493(1993)121<0375:AOSCIE > 2.0.CO;2.

Riemann-Campe, K., L. Fraedrich, and F. Lunkeit, 2009: Global climatology of convective available potential energy (CAPE) and convective inhibition (CIN) in ERA-40 reanalysis. Atmos. Res., 93, 534-545, https://doi.org/10.1016/j.atmosres.2008.09.037.

Sanders, F., and J. R. Gyakum, 1980: Synoptic-dynamic climatology of the "bomb." Mon. Wea. Rev., 108, 1589-1606, https://doi.org/ 10.1175/1520-0493(1980)108<1589:SDCOT>2.0.CO;2.
Schultz, D. M., and P. N. Schumacher, 1999: The use and misuse of conditional symmetric instability. Mon. Wea. Rev., 127, 2709-2732, https://doi.org/10.1175/1520-0493(1999) 127<2709:TUAMOC $>2.0 . \mathrm{CO} ; 2$.

Seltzer, M. A., R. E. Passarelli, and K. A. Emanuel, 1985: The possible role of symmetric instability in the formation of precipitation bands. J. Atmos. Sci., 42, 2207-2219, https://doi.org/ 10.1175/1520-0469(1985)042<2207:TPROSI >2.0.CO;2.

Serreze, M. C., 1995: Climatological aspects of cyclone development and decay in the Arctic. Atmos.-Ocean, 33, 1-23, https:// doi.org/10.1080/07055900.1995.9649522.

_ 2009: Northern hemisphere cyclone locations and characteristics from NCEP/NCAR reanalysis data, version 1 . National Snow and Ice Data Center, Boulder, CO, digital media, accessed 25 October 2016, https://nsidc.org/data/nsidc-0423.

, F. Carse, R. G. Barry, and J. C. Rogers, 1997: Icelandic low cyclone activity: Climatological features, linkages with the NAO, and relationships with recent changes in the Northern Hemisphere circulation. J. Climate, 10, 453-464, https://doi. org/10.1175/1520-0442(1997)010<0453:ILCACF>2.0.CO;2.

Shutts, G. J., 1990a: The dynamical structure of some North Atlantic depressions simulated by the fine-mesh model. Met Office Science Note 17, 75 pp.

- 1990b: SCAPE charts from numerical weather prediction model fields. Mon. Wea. Rev., 118, 2745-2751, https://doi.org/ 10.1175/1520-0493(1990)118<2745:SCFNWP $>2.0 . C O ; 2$.

Simmons, A. J., K. M. Willett, P. D. Jones, P. W. Thorne, and D. P. Dee, 2010: Low-frequency variations in surface atmospheric humidity, temperature, and precipitation: Inferences from reanalyses and monthly gridded observational data sets. J. Geophys. Res., 115, D01110, https://doi.org/10.1029/2009JD012442.

Stone, P. H., 1966: On non-geostrophic baroclinic stability. J. Atmos. Sci., 23, 390-400, https://doi.org/10.1175/1520-0469(1966) $023<0390$ :ONGBS $>2.0$.CO; 2 .

, 1967: An application of baroclinic stability theory to the dynamics of the Jovian atmosphere. J. Atmos. Sci., 24, 642-652, https://doi. org/10.1175/1520-0469(1967)024<0642:AAOBST>2.0.CO;2.

_ 1971: The symmetric baroclinic instability of an equatorial current. Geophys. Fluid Dyn., 2, 147-164, https://doi.org/ 10.1080/03091927108236055.

Subrahmanyam, K. V., K. K. Kumar, and A. N. Babu, 2015: Phase relation between CAPE and precipitation at diurnal scales over the Indian summer monsoon region. Atmos. Sci. Lett., 16, 346-354, https://doi.org/10.1002/asl2.566.

Tamarin, T., and Y. Kaspi, 2017: Mechanisms controlling the downstream poleward deflection of midlatitude storm tracks. J. Atmos. Sci., 74, 553-572, https://doi.org/10.1175/JAS-D-16-0122.1.

Thorpe, A. J., and K. A. Emanuel, 1985: Frontogenesis in the presence of small stability to slantwise convection. J. Atmos. Sci., 42, 1809-1824, https://doi.org/10.1175/1520-0469(1985) 042<1809:FITPOS > 2.0.CO;2.

Xie, P., and P. A. Arkin, 1997: Global precipitation: A 17-year monthly analysis based on gauge observations, satellite estimates, and numerical model outputs. Bull. Amer. Meteor. Soc., 78, 2539-2558, https://doi.org/10.1175/1520-0477(1997) 078<2539:GPAYMA $>2.0$. CO;2.

$\mathrm{Xu}, \mathrm{Q} ., 1986$ : Conditional symmetric instability and mesoscale rainbands. Quart. J. Roy. Meteor. Soc., 112, 315-334, https:// doi.org/10.1002/qj.49711247203.

Zamora, R. A., R. L. Korty, and M. Huber, 2016: Thermal stratification in simulations of warm climates: A climatology using saturation potential vorticity. J. Climate, 29, 5083-5102, https:// doi.org/10.1175/JCLI-D-15-0785.1. 